\title{
Nombres vernáculos de plantas leñosas en León
}

La provincia de León limita con Castilla, Asturias y Galicia y tiene en común paisajes y costumbres con cada una de las regiones citadas. Debido a la emigración, he encontrado pueblos despoblados y casas de piedra o adobe cerradas y abandonadas desde las montañas de Riano a las de Luna y desde la Cabrera a la Maragatería y Tierra de Campos. He recogido las denominaciones de los diferentes vegetales, durante la primavera de 1982 y 1983, período óptimo en el que el desarrollo de la vegetación es total, ya que el agostamiento comienza durante el verano y la retención del crecimiento se da durante el invierno.

Las encuestas se han hecho 'in situ', fotografiando la planta, transcribiendo el nombre vernáculo y luego identificando los ejemplares recogidos en el laboratorio de botánica. He tenido que hacer numerosas consultas para la identificación científica de las especies que menciono. Al mismo tiempo, he recogido el mayor número de nombres vernáculos de las plantas leñosas y de las herbáceas silvestres con sus variantes léxicas o fónicas. En las denominaciones de las herbáceas es frecuente el uso erróneo de nombres vulgares, lo cual es lógico debido a la transmisión oral y a la diferente capacidad visual de los informantes. A veces se utiliza el mismo nombre para plantas distintas y éstos se deforman y cambian. He podido comprobar que los varones, por lo general, conocen las plantas mejor que las mujeres, excepto en las zonas donde ellas no están desligadas de las tareas agrarias y comparten las labores del campo, que los niños corrigen al padre cuando éste deforma el nombre, e incluso, los mayores a los compañeros porque 'ya no se dice así'. Al recorrer todas las zonas de León para verificar los diferentes términos que, a pesar de los reiterados temores, siguen vigentes en boca de los mayores, he podido comprobar también la veracidad de nuestros dialectólogos al dar los nombres, pero la mayoría de las descripciones que han hecho, sobre todo de las plantas herbáceas, son generalmente inútiles a la hora de identificarlas.

El clima, determinante de la aparición de la vegetación, somete a un escaso régimen hídrico a parte de la provincia, salvo zonas regables y vegas de ríos. Por otro lado, las distintas comarcas no tienen la misma situación climática, ya que en las partes montañosas y parameras la destrucción 
de la vegetación ha erosionado el suelo y se ha producido una degradación irreversible y con ella ha desaparecido la planta y se ha olvidado el nombre; el conocimiento profundo queda en manos de botánicos y especialistas. Incluyo también los frutales que en muchas ocasiones se encuentran asilvestrados y también plantas arbustivas que pueblan pastizales, matorrales y antiguas tierras de labor abandonadas en la actualidad.

Siempre doy el nombre oficial, la denominación científica y la familia botánica, hago una breve descripción elaborada de los distintos botánicos consultados y doy los nombres de uso común de cada especie y el área donde he recogido el nombre. No es muy copioso el vocabulario obtenido, pero las voces registradas son actuales y están hechas con exactitud fonética y geográfica, aunque aquí sólo se presenta la transcripción literal. Por otro lado, el conocimiento de los diferentes nombres de las diversas comarcas nos da una visión del leonés actual, de su progresiva y casi total desaparición debido a la concurrencia de hablas prestigiosas y a la acción aniquiladora de los medios de comunicación; pocas zonas hay que resistan a esta acción niveladora de la lengua oficial, aunque en algunas comarcas una serie de variedades asturleonesas resisten en el occidente las incrustaciones gallegas y en el oriente, las cántabras. Para mejor estructurar los diferentes nombres, parte de los cuales no son exclusivos de la región, pues se dan en otras partes de España, he dividido la provincia en seis zonas cuyas diferencias son considerables.

(BEC). Es una zona que comprende la Bañeza, Esla y Tierra de Campos, está totalmente castellanizada y sus tierras son semejantes a las llanuras castellanas. Está regada por los ríos Órbigo, Esla y Cea, en sus riberas y vegas hay abundante vegetación, y al mismo tiempo posee marcados contrastes debido a oteros y páramos leoneses.

Los puntos encuestados son los siguientes: Castrocalbón, San Esteban de Nogales, Campo de Villavidel, Morilla, Ardón, Valdemimbre, Matadeón, Urdiales del Páramo, Villarrín del Páramo, Pajares de los Oteros, Valdesaz, Cubillas de los Oteros, Fresno de la Vega, Valencia de Don Juan, Villapadierna, Valdoré, Vidanes y Valderas.

(MyA). La Magaratería y Astorga son tierras con gentes de espíritu patriarcal, cuyo clima, suelo y producción son también castellanos, pero, con comarcas individualizadas, al pasar del páramo a la montaña, caracterizadas por diferentes hablas, usos y costumbres. Forman una zona rodeada en el norte por sierras y valles, y por el sur las alineaciones montañosas la separan del Bierzo y la Cabrera. Los puntos encuestados son los siguientes: Brazuelo, Pradorrey, Santa Colomba de Somoza, Rabanal del Camino, Destriana de Valduerna.

(MR). La Montaña de Riaño es una de las zonas más pintorescas de León donde el terreno cultivable escasea y la ganadería tuvo una considerable importancia. La emigración de la población hacia los centros urbanos e industriales ha contribuido a desarticular la vida rural y a reducir el trabajo 
eliminando pastos y ganado. Por estar muy comunicada con Asturias y Santander, tiene un especial interés recoger la terminología propia. Los puntos encuestados son los siguientes: Las Salas, Horcadas, Boca de Huérgano, Siero de la Reina, Cuenabres, Retuerto, Oseja de Sajambre.

(ML). La Montaña de Luna es una región de carácter conservador y sus pueblos están unidos por estrechos lazos que hacen que tengan idénticas costumbres y un habla igual, constituyendo una unidad dialectal con matices semejantes. El léxico, aunque manifiesta resistencia al cambio, está en trance de desaparecer o tiende a modificarse. Se da una tendencia arcaizante, que tiene resabios de bable y gallego, y otra innovadora del castellano. Durante siglos apenas hubo modificaciones y actualmente debido a los medios de comunicación, los cambios son considerables. Es frecuente el uso de vocablos conservados íntegramente o ligeramente modificada su forma latina, como nisu, prunu, etc. Los puntos encuestados son los siguientes: Pobladura de Luna, Sena de Luna, Villafeliz, San Emiliano de Babia, Torrebarrio de Babia, Cospedal de Babia, Carrasconte de Babia, Llamas de Laciana.

(B). El Bierzo es una región de tránsito entre la meseta central y la región gallega y forma una unidad geográfica de caracteres inconfundibles. Quedan pocos rasgos y voces del gallego portugués, pues el castellano invade el centro y el occidente de la región, pero aún se emplea un habla con abundantes originalidades. Se pueden apreciar los cambios de estructura de las voces castellanas a las gallegas y dónde confluye el habla gallega y el habla leonesa. La flora y la vegetación tienen más afinidades con Galicia que con la meseta. Los puntos encuestados son los siguientes: Camponaraya, Cacabelos, Corbón del Sil, Cuevas del Sil, Pereje, Pieros, Trabadelo, Las Ventas de Alvares, Torre del Bierzo.

(CyV). La Cabrera y Valdería son comarcas próximas donde no existen accidentes geográficos que marquen divisiones; en cambio el carácter montañoso de la Cabrera ha fomentado la incomunicación. En esta originalísima región los habitantes han vivido dedicados exclusivamente a las labores del campo, pues es la base de la pequeña economía de todas las familias. La pobreza de esta tierra consume los esfuerzos y el trabajo de estas gentes para poder sobrevivir. La emigración es constante y el aislamiento en el que suelen vivir se acentúa, ya que las comunicaciones con las regiones lindantes son escasas y difíciles. Los puntos encuestados son los siguientes: Tornero de la Valdería, Morla de la Valdería, Manzaneda, Truchas y Truchillas.

Agradezco la ayuda y observaciones de Angel Penas Merino, Catedrático de Botánica de la Universidad de León, y Ginés López González, investigador del CSIC en el Jardín Botánico de Madrid. 


\section{ABEDUL}

(Betula pubescens)

Betuláceas

Árbol de tronco delgado y corteza lisa, con hojas puntiagudas y bordes aserrados, dispuestas en ramilletes colgantes, y con semillas aladas. Florece de abril a mayo. Se cría en suelos húmedos y zonas montañosas. Su corteza se usa para curtir pieles y se han empleado las hojas, yemas y savia contra las infecciones urinarias y la artrosis.

Denominaciones en León (DL): abedul (BEC), (MR), (ML), (B), (CyV); abidul (ML), (MR), (B); bidul (B), (ML); bedul (ML); bidueiro (B).

Véase otras denominaciones (OV): bidureiro (bable occid.) y bidueiro (gall.), Acevedo; abidul (Santander), García Lomas; id. (La Lomba), Morán; id. (Lena), Neira; id. (Pas), Penny; abedurio (A. Aller), Rodríguez-Castellano); abedugu (Colunga), Vigón; bidul (Sisterna), J. A. Fernández; id. (Valle Gordo), Rubio; alba (A. Ribagorza), Haensch; abedul en ALEANR, III, *399.

\section{ABROJOS}

(Genista hystris)

Leguminosas

Arbusto achaparrado y espinoso con tallos largos y rastreros terminados en espino, hojas alternas y elípticas; las flores, amarillas y amariposadas, nacen en las axilas de las ramas viejas. El fruto es una legumbre alargada. Florece a partir de mayo y se desarrolla en suelos poco profundos y pedregosos.

DL: abrojos (BEC); abruecbus (ML).

OV: abriojal 'abrojal' y abriojo 'abrojo' (Rioja), Goicoechea; caramoño 'fruto del abrojo' (Orihuela), Guillén; abreojos (T ribulus terrestris) (Cuenca), Calero.

\section{ACEBO}

(Ilex aquifolium)

Aquifoliáceas

Arbusto con corteza lisa y hoja coriácea con dientes espinosos y margen ondulado. Las flores, blancas o rosadas, nacen agrupadas de las axilas foliares. El fruto es una baya de color rojo. Florece en abril y se cría en setos, matorrales y bosques de suelos frescos. De su corteza se obtiene la liga. Se han utilizado las hojas por tener propiedades diuréticas y los frutos, tóxicos para el hombre, como purgantes y vomitivos. 
DL: acebo (BEC), (MR), (ML), (B), (MyA); aceo (BEC) y (MR); acebro y cebro (CyV).

VO: acebo y acebu (bable occid.), Acevedo; briscu (Cabranes), Canellada; id. (Cabo Peñas), Díaz; aceba 'var. de acebo sin púas' (Santander), García Lomas; id. (Pas), Penny. Su agrupación forma el acebal (Bierzo), G. Rey; acebedal o acebosa (A. Aller), Rodríguez-Castellano; carrescu (Lena), Neira; acibu (Lena), Neira y (Pas), Penny; acebuche (Colunga), Vigón; sardón, xardón y xardonera 'planta grande de acebo' (bable occid.), Rodríguez-Castellano; id. (Sisterna), J. A. Fernández; aceo (Tejerina), Villarroel y (Sajambre), Fernández González; acebiño (Tenerife), Alvar; grévol (A. Ribagorza), Haensch; acegu (Cabrales), Fernández-Cañedo; acebo (Cuenca), Calero; e id. en ALEANR, III, *399.

\section{ACEROLO}

(Crataegus azarolus)

Rosáceas

Arbolillo de madera durísima, de ramas frágiles y espinosas el silvestre, con hojas aovadas muy hendidas y el margen aserrado. El fruto, la acerola, áspero, carnoso de color amarillo o rojo anaranjado es acídulo y dulce. Florece en mayo y madura sus frutos en septiembre. Se cría en bosques y setos de suelos ácidos. Por fermentación se obtienen bebidas alcohólicas y vinagres; se ha utilizado contra la diarrea y la disentería.

DL: acerolo, cirolin y cirulillo (BEC).

OV: cerollero 'acerolo' y cerolla 'acerola' (Aragüés), González Guzmán; acerola en ALEANR, XI, 1546.

\section{AGRACEJO}

(Berberis vulgaris)

Berberidáceas

Arbusto de largas y delgadas ramas con espinas trifurcadas. Las hojas son elípticas con bordes aserrados y espinosos. Las flores de color amarillo dorado, agrupadas en racimos, despiden un fuerte olor. El fruto es una pequeña baya oval de color rojo anaranjado. Florece en mayo y se cría en setos y declives montañosos. Su corteza estimula la secreción biliar, es digestiva y sus hojas astringentes y diuréticas.

$\mathrm{DL}$ : vinagrera, espino (BEC); agreilla y abrilla (ML); granado (BEC), (B); escabrión (B).

VO: agracio y acracial 'lugar poblado de agracios o agracejos' (Santander), García Lomas; alguese (Andal), Alcalá, V.; agranzón 'fruto comestible' (Rioja), Goicoechea; agraciu (Pas), Penny; acracejo, alrera, arlera, alro y arlo (Cuenca), Calero. 


\section{6. ÁLAMO BLANCO}

(Populus alba)

Salicáceas

Árbol robusto y corteza blanco grisácea, de hojas palmeadas y alternas pecioladas, cubiertas por el envés de un fieltro blanco. Las ramas jóvenes y las yemas resinosas están cubiertas de pelillos. Sus ametos colgantes son verdosos. Florece en abril y se cría en riberas de ríos y sotos. Se planta en ciudades y jardines y es de rápido crecimiento.

DL: álamo, álamo blanco y chopo (todos).

OV: carolin 'álamo más grande y fuerte que el corriente con la hoja blanca por el envés' (Cabranes), Canellada; albar (Bielsa), Badía; palero, 'chopo o álamo' (A. Aller), Rodríguez-Castellano; a la 'chopera o alameda que brota espontáneamente, la llaman trasgal (Bierzo), García Rey; álamo en ALEANR, III, 398 y ALES, 240.

\section{ALBARICOQUERO}

(Prunus armeniaca)

Rosáceas

Arbusto con ramas ascendentes y rojizas, hojas acorazonadas con bordes aserrados, flores blancas o rosa pálido y cuyo fruto, el albaricoque, es una drupa globulosa anaranjada. Florece por febrero y se cría asilvestrada en setos y ribazos. Para su cultivo se utiliza como patrón el almendro y a veces el ciruelo. Hay múltiples variedades.

$\mathrm{DL}$ : albaricoque (BEC), (B); albérchigo y alberchigal. Var. -piescol-a, pavio/-a y moniquis (BEC); paviar (B); piescu (ML).

VO: abercoquero, abercoque, damasquillo, coque, tonto (Andal.), Alcalá V.; piescu 'albérchigo' (Badía), Álvarez; abricoquero 'fruto del albaricoque' (Tenerife), Alvar; pavía (Bierzo), García Rey; abercoquero 'albaricoquero' y abercoque 'albaricoque' (Orihuela), Guillén; id. (Villena), Torreblanca; pescal y piescal variedad de albaricoquero y piescu 'especie de albaricoque (Cabrales), Fernández-Cañedo; bobos 'albaricoques' (Extremadura, Tierra de Barros), Murga; albaricoque en ALC, I, 56; ALEA, II, 353; ALEANR, III, 361; ALEICAN, I, 250; ALVA, 55; y albérchigo en ALEA, II, *354; ALEANR, III, 365; ALES, 215.

\section{ALCAPARRA}

(Capparis spinosa)

Caparáceas

Arbusto espinoso con tallos tendidos, hojas alternas y ovales con el borde entero y espinas en la base. Flores de color blanco o rosado grandes y axilares y cuyo fruto, alcaparrón o alcaparra, es una baya portadora de 
semillas. Florece en primavera y se cría en terrenos áridos y pedregosos. Sus brotes florales y frutos se han empleado para condimento y con fines terapéuticos como antiespasmódico intestinal y contra las dificultades renales y de las vías urinarias.

DL: alcaparra (BEC).

VO: taparote 'alcaparra' (prov. Almería), Alcalá V.; pegajillo (Tenerife), Alvar; tápena 'alcaparra y su flor' (Orihuela), Guillén; id. (Villena), Torreblanca; tapanera, 'mata de la alcaparra', caparra y taillera, 'alcaparra' y tapenón 'alcaparrón' (Orihuela), Guillén; tápana o alcaparra (La Roda), Chacón; alcaparra en ALEA, II, 300.

\section{ALCORNOQUE}

( Quercus suber)

Fagáceas

Árbol de hoja persistente, semejante a la encina. Al quitar su gruesa corteza profundamente agrietada, la nueva es de un intenso color rojo oscuro. Las hojas son coriáceas, aovadas con el margen ondulado y entero. Las flores amarillas cuelgan agrupadas en la parte final de los ramilletes. Florece en primavera y su fruto, la bellota, madura en septiembre. La corteza o corcho es rica en tanino y los frutos se utilizan para piensos.

$\mathrm{DL}$ : alcornoque (BEC), (B); alcorque $(\mathrm{CyV})$; corchero $(\mathrm{BEC})$.

OV: sufreira (bable occid.), Acevedo; arcornoqui (Coria), Cummins; alcornoque en ALEA, II, 372; ALEANR, III, *392.

\section{ALGARROBO}

(Ceratonia siliqua)

Leguminosas

Árbol perennifolio de tronco grueso y corteza gris oscura, con hojas de foliolos coriáceos y ovales de borde entero. Las flores son de color purpúreo y el fruto, la algarroba, es alargado y comprimido de color negro rojizo. Florece a partir de julio y se cría en zonas templadas. Utilizase para piensos y para obtener goma en usos industriales. Las hojas y la corteza al ser astringentes se usan contra la diarrea, y el fruto cocido, como laxante.

DL: algarrobo (todas).

OV: albarrobo (Bielsa), Badía; gaprubia (Andal.), Alcalá V.; algarrobal y algarrofal (Rioja), Goicoechea; garrotero (Orihuela), Guillén; id. (Villena), Torreblanca; id. (La Roda), Chacón; garroba (El Rebollar), Iglesias; algarrobo en ALEANR, III, *353; ALEICAN, I, *256. 


\section{ALIGUSTRE}

(Ligustrum vulgare)

Oleáceas

Arbusto ramoso caducifolio con hojas opuestas, lanceoladas y bordes enteros; flores blancas, densamente agrupadas en racimos y olorosas. El fruto es una baya negra, de carne aceitosa y tóxica. Florece a partir de mayo y se cría en márgenes de ríos, setos y laderas frescas. Los frutos y la corteza se han utilizado para colorear vino y las hojas contra la diarrea.

DL: aligustre, abusto y sebe de jardin (BEC).

OV: cornampuya (Cabranes), Canellada; cornapuya (Colunga), Vigón; cormapú (Lena), Neira; pišasang y sanguine(t) (A. Ribagorza), Haensch; cita en leonés sanguñera 'ligustro'.

\section{ALISO}

(Alnus glutinosa)

Betuláceas

Árbol con corteza fisurada pardo oscura, hojas redondeadas, elípticas con borde sinuoso y dentado; flores blancas en amentos cilíndricos y alargados; los frutitos están comprimidos y alados. Se cría en la ribera de los ríos y suelos con humedad. Se ha empleado contra el reumatismo, inflamaciones de boca y en cataplasmas, para disminuir la secreción láctea.

DL: aliso (BEC), (ML), (MyA), (B); bumeiro (B), (ML), (CyV), (MyA); aleso, bomeiro (CyV); alisio (BEC); bumero (BEC), (MyA), (CyV), (B); (b)omero (MyA), (B), (CyV) y (BEC); (b)aumero/-a (B).

OV: humero (Maragatería), Alonso Garrote; alisa (Santander), García Lomas; id. (Pas), Penny; bumiro (Lena), Neira; bumeru y oumeiru (Colunga), Vigón; umeiro (bable occid.), Rodríguez-Castellano; bumeiro (Valle Gordo), Rubio; umeiru (Sisterna), J. A. Fernández; alisio y aliso (Sayago), Borrego; aliso en ALEANR, III, *399.

\section{ALMENDRO}

(Prunus a mygdalus)

Rosáceas

Árbol de corteza rugosa, hojas alternas y lanceoladas. Sus flores son blancas o rosadas y los frutos ovales, de color verde en cuyo interior está la semilla o almendra, protegida por una cáscara. Su floración es muy temprana; sus almendras son utilizadas en pastelería y con su aceite, se preparan cremas contra quemaduras. Las amargas son tóxicas.

$\mathrm{DL}$ : almendro (BEC), (B), (CyV), (MyA); almendral, almendrucal y almendrugal (BEC). 
Vgr. almendro amargo y almendro bravo (BEC).

OV: arzollo 'almendro silvestre' (Andal.), Alcalá, V.; amellet (A. Ribagorza), Haensch; almendrolero y armendolero (Villena), Torreblanca; guapero 'almendro silvestre' (Extremadura), Murga; almendro en ALC, I, 84; ALEANR, III, 349; ALEICAN, I, 258; ALES, 194; ALVA, 82.

\section{ARÁNDANO}

(V a c i u m m y tillus)

Ericáceas

Arbustillo muy ramificado con tallos parcialmente leñosos; hojas ovales, aserradas, alternas y de peciolo corto. Las flores de color verde amarillento o rosadas son axilares. El fruto es una baya negra azulada y comestible. Florece en junio y se cría en brezales y bosques. Con su jugo se aromatizan aguardientes y es utilizado contra las hemorroides y los gases intestinales.

$\mathrm{DL}$ : arándano (BEC), (ML), (B), (MyA), (CyV); arandilla (BEC); arandanera (ML), (BEC); arráspano (MR).

VO: arando y arándano (bable occid.), Acevedo; rasponera o raspanorio, raspaniza o raspaneta (Santander), García Lomas; arandanera (La Lomba), Morán; id. (Valle Gordo), Rubio; id. (bable occid.), RodríguezCastellano; arandaneira (Sisterna), J. A. Fernández; anabia 'arándano, fruto de esa planta' y ganabia 'anabia' 'arándano' (Rioja), Goicoechea; rasponera y ráspanu 'fruto' (Pas), Penny; anavia 'fruto del arándano' (Anguiano), Echaide.

\section{ARCE}

(Acer pseudoplatanus)

Aceráceas

Árbol de corteza lisa y grisácea con hojas opuestas, divididas en lóbulos dentados y acorazonados en la base. Sus flores dispuestas en racimos colgantes son de color verdoso amarillento y sus frutos están dotados de sámaras. Se cría en setos, bosques y suelos frescos. La corteza, hojas y fruto se han utilizado como medicinales para combatir diarreas, disenterías y enfermedades oculares.

$\mathrm{DL}$ : arce (BEC); prádano (B) y (MyA); plágano (MR), (B).

OV: acirón (Bielsa), Badía; azar y asar 'planta acerínea, variedad del arce, más pequeño, de flores de corimbos colgantes y fruto globoso' (Andal.), Alcalá, V.; prádana (Sisterna), J. A. Fernández; alsirón, alsiró y alziró 'arce campestre' (A. Ribagorza) Haensch; arce en ALEANR, III, *399. 


\section{ARGAÑA}

(Erica cinerea)

Ericáceas

Arbustillo erguido y ramificado con hojas lineares en verticilos, lampiñas y verdeoscuras. Flores de color violáceo o púrpura formando un denso racimo. Fruto globoso y lampiño. Florece en marzo y se cría en declives secos y brezales. Se han empleado sus flores contra las afecciones renales.

$\mathrm{DL}$ : argaña (BEC); urce colorada (CyV); ur y brezo negral (de flor encarnada) (MyA).

OV: argaña (Cabo Peñas), Díaz; berezo (Santander), García Lomas; bermejuela (Andal.), Alcalá, V.; urcia 'brezo'. V. Argaña (Cabo Peñas) Díaz.

\section{AULAGA}

(Genista scorpius)

Leguminosas

Arbusto espinoso muy ramificado y provisto de fuertes espinas punzantes; hojas lisas, alternas lanceoladas y terminadas en púas. Flores de color amarillo situadas en las axilas de las espinas; el fruto es una legumbre alargada y comprimida. Florece a partir de enero y se cría en suelos soleados, pedregosos y frescos. Se han utilizado sus flores fermentadas y con azúcar para restablecer las fuerzas y eliminar las obstrucciones intestinales.

DL: arcilaga, ardilaga, artilaga, aulaga, ilaga (BEC); ilaga y cardina (ML); árguma y zulaga (MR).

OV: gancella 'árgoma o aulaga'. Se roza en los montes y sirve para mullir las cuadras y corradas (bable occid.), Acevedo; cotolla (Cabranes), Canellada; allagón (Jaca), Alvar; aliaga (Bielsa), Badía; albulaga y arbulaga (Andal.), Alcalá, V.; ilaga (Villacidayo), Millán; abulaga, albulaga y ulaga (Tenerife), Alvar; eschelagra y chelagra (A. Ribagorza), Haensch; laga (Bureba), González-Ollé; ulaga, aliaga y olagacino; ulagar e ilagar 'aliagar' (Rioja), Goicoechea; oblaga y olaga (Anguiano), Echaide; abularga (Coria), Cummins; abulaga (Extrem.), Murga; ulaga (El Rebollar), Iglesias; aliaga (Cuenca), Calero; aulaga, en ALA, 123; ALC, I, 148; ALEA, II, 308; ALEANR, III, 284; ALEICAN, I, 210; ALES, 161; ALVA, 146.

\section{AVELLANO}

(Corylus avellana) 


\section{Coriláceas}

Arbusto ramificado desde la base, de corteza lisa y hojas acorazonadas, puntiagudas y márgenes aserrados. Flores amarillas en espigas colgantes y fruto comestible, la avellana, que se obtiene cuando la cáscara y vaina tienen color marrón. Se cría en umbrías, setos y barrancos. Se han utilizado sus hojas como depurativas y su corteza como febrífuga y cicatrizante.

DL: avellano o avellanal (BEC), (MyA); avillano (B); ablanal, ablanar y ablano (ML), (MR).

OV: avellau y avillao 'avellano'. En Oriente, ablanu y aviyaa 'avellana'; y ablana en Oviedo y Colunga (bable occid.), Acevedo; ablanal y ablanar 'avellano'; ablana 'avellana' y ablanu avellana pequeña, dura y de forma alargada (Cabranes), Canellada; buganal 'lugar donde abundan las plantas de avellano' (Maragatería y A), Alonso Garrote; avellanera (Aragüés), González Guzmán; ablanal 'avellano' y ablana 'avellana' (A. Aller), Rodríguez-Castellano; id. (Babia y Laciana), Guzmán Álvarez; id. (La Lomba), Morán; id. (Cabo Peñas), Díaz; ablanero 'avellano', ablaneros 'avellanedos', son silvestres y su fruto se llama ablenu (Lena), Neira; ablanar 'avellano', ablana 'avellana' (Colunga), Vigón; abiyaneiro, abiyanal, abiyaneira, ablanal, ablaneiro, ablano, abrao y parra, el fruto ablana y el avellanal ablaneo y parriru (Bable occid.), Rodríguez-Castellano; ablanal y ablano 'avellano' y ablana 'avellana' (Sajambre), Fernández González; braneiru 'avellano', abrau 'avellano silvestre que no da avellanas' y abrana 'avellana' (Sisterna), J. A. Fernández; avellanera y vellanera (A. Ribagorza), Haensch; abeyar 'avellano' y ablanu 'avellana' (Cabranes), Fernández-Cañedo; avellanal 'avellano' (Villacidayo), Millán; avillanu (Pas), Penny; avellanero (Villena), Torreblanca; avellano y avellanero (Sayago), Borrego; avellano en ALA, 150; ALC, I, 180; ALEANR, III, *348; ALES, 195; ALVA, 178.

\section{BONETERO}

(Evonymus europaeus)

Celastráceas

Arbusto con corteza gris, lisa y ramillas cuadrangulares, con hojas opuestas, ovales, o elípticas dentadas. Flores dispuestas en racimos pedunculados de color blanquecino o verdoso. La semilla está cubierta de una envoltura carnosa anaranjada. Florece en abril y se cría en setos, matorrales y en general en bosques caducifolios. Se cultiva como planta ornamental y se extrae de sus frutos un colorante vegetal.

DL: boj, boj montés, boz, boje (BEC), (MyA), (B).

OV: bo"xe (bable occid.), Acevedo; boje (Maragatería y A), Alonso Garrote; id. (Andal.), Alcalá, V.; id., Rodríguez-Castellano; id. (Cuenca), 
Calero; buiso (Bielsa), Badía; buš areta (Jaca), Alvar; vólivo (Andal.), Alcalá, V.; buchos 'boj' y buchar 'bujedo' (Aragüés), González Guzmán; buiš o, buiš, boiš (A. Ribagorza), Haensch; bujo 'boj silvestre' (Rioja), Goicoechea; boj (Sayago), Borrego; boj(es) en ALA, 241; ALC, II, 285; ALEANR, III, 288; ALVA, 281.

\section{BRECINA}

(Calluna vulgaris)

Ericáceas

Arbusto de cepa leñosa y muy ramificado; hojas diminutas y linearlanceoladas; flores dispuestas en racimos terminales de color lila o rosado. El fruto es una cápsula redondeada y abridera. Florece en verano y se cría en brezales, pantanos, suelos pobres y arenosos. Ha sido utilizada como planta melífera, para hacer fuego, cocer pan en los hornos y fabricar escobas. Sus ramas y flores son astringentes y con ellas se han combatido enfermedades de las vías respiratorias.

$\mathrm{DL}$ : urce, urz, orbezo, berezo y brecina (BEC); uces (B); urcina, cherliz, charliza (CyV).

OV: brecina, planta ericácea de ramas lampiñas, hojas lineales obtusas cuaternas y flores en umbelitas rosadas y brecenal 'terreno poblado de brecina' (Granada), Alcalá, V.; gorbizo 'brezo bajo y de flor morada' (A. Aller), Rodríguez-Castellano; brécol, brócal (A. Ribagorza), Haensch; brezo en ALEA, II, *310; ALEANR, III, *399; ALES, 241.

\section{BREZO/URCE}

(Eric a vagans)

Ericáceas

Arbusto muy ramificado, con racimos flojos y cilíndricos terminados por un penachito de hojas lineares; las flores son de color lila pálido o blancas con largos pedúnculos florales. Es muy común en León. De gran floración, se cría en montes de ribera alta, matorrales y otras especies arbustivas.

DL: brezo (MyA), (BEC), (CyV), (MR); urce (BEC), (MR), (ML), (CyV), (MyA), (B); urz (MyA), (B); uz (CyV), (ML); uces (BEC); ur (ML); brezo azul (BEC); urce de flor morada (B); brezo o urz negral y tuéngano (MyA); amadio, brezo enano o urz (MR); urce griñal o de flor morada (CyV).

OV: urz 'planta de brezo con hojas lineales y duras'; urcia (Maragatería y A), Alonso Garrote; furce, turuégano 'urce' y ucedo 'sitio poblado de urces' (Bierzo), G. Rey; urz o urce (La Lomba), Morán; id. (Valle Gordo), Rubio; id. (Villacidayo), Millán. 


\section{BREZO ALBARIZO}

(Erica arborea)

Ericáceas

Arbusto ramoso y blanquecino por estar cubierto de pelillos, con hojas muy estrechas y lineares, agrupadas en verticilos. Las flores son de color blanco o rosado y largamente pedunculares. Su fruto es seco en cápsula abridera. Florece en marzo y se cría en matorrales, colinas y brezales frescos y umbrosos. Su madera se ha utilizado como combustible y para fabricar pipas. Es la mayor de las urces leonesas.

DL: brezo o urce (BEC); brezo albar, urz albar y albarona (MyA); urce blanca, urza albar, brezo oloroso (CyV); albarón (B).

OV: brezo albarizo, brezo blanco, planta de Sierra Morena (Huelva), Alcalá, V.; Caxigu (Colunga), Vigón; albaronas es el brezo de flor blanquecina ( $\mathrm{u}$ le $\mathrm{x}$ a $\mathrm{lb}$ a) en la frase 'urces albaronas o albares' para distinguirlo del de flor morada (ulex viola cea). 'Las urces albaronas crecen más altas y tienen más claras las ramas que sus congéneres de flor morada' (Maragatería y A.), Alonso Garrote; urcia 'brezo' y urcial 'campo de brezos', ganzo y ganzo blanco 'brezal' (bable occid.), Rodríguez-Castellano.

\section{BREZO DE ESCOBAS}

(Erica scoparia)

Ericáceas

Arbusto muy ramificado con vástagos grisáceos y lampiños; hojas con verticilos lineares y dos surcos en el envés. Flores diminutas y abundantes de color amarillo verdoso dispuestas en largos y estrechos racimos espiciformes. Florece en diciembre y se cría en brezales, colinas y lugares soleados sin labrar.

DL: brezo de escobas, urce de escobas (MyA); escobas o brezo (CyV).

OV: escoba 'el brezo de escoba' (Bierzo), G. Rey; berizu 'brezo. Toda planta de monte que se puede rozar. Hay una variedad más fina que es el beriénzanu. 'Se emplea para cama del ganado como estru y también para hacer escobas' (Santander), García Lomas; id. (Cabranes), Canellada; escobar 'terreno que produce escobas' (La Lomba), Morán; urcias 'urces', también gorbiz 'brezo' y gorbicial 'terreno poblado de gorbices' (Lena), Neira; beriénzanu, 'E ric a s coparia o brezo de escobas. Usual en las parroquias de Libardón y Carrandi' (Colunga), Vigón; brezo 'brezo, la escoba propiamente dicha' (Bureba), González Ollé; bericiu y beriénzanu (Cabo Peñas), Díaz; berizu 'brezo'; berezal 'brezal' (Pas), Penny; berozo (Anguiano), Echaide; berezu (Coria), Cummins. 


\section{CAMBRONERA}

(Echinospartum bardenesii)

Leguminosas

Arbusto denso, muy espinoso y con ramas estriadas, hojas opuestas engofiadas, lampiñas por el haz y vellosas por la cara inferior. Las flores son amarillas, reunidas en parejas en el extremo de las ramas. El fruto es una legumbre vellosa largamente aovada. Florece en junio y se cría en suelos poco profundos, pedregosos y lugares secos y soleados.

DL: cambronera, escambrión (ML); espino escambrión, escambrón (B); espino cambrión (MyA).

OV: espinu escambrión 'planta más pequeña que el espino corriente (V. espinu garbanceiru) sumamente erizada de púas hacia abajo' (Babia y L.), Álvarez; capronera 'especie de zarza. Se distingue de la barza que corresponde al castellano barza o zarza', comp. barzal (Bielsa), Badía; espino cambrón (Andal.), Alcalá, V.; artu albar o artu 'cambronera o espino de flores blancas' (Colunga), Vigón; iscambrón 'espino', iscambruneiru 'zarzal' (Sisterna), J. A. Fernández; escambruneiro 'mata con espinas grandes y no dan fruto' (bable occid.), Rodríguez Castellano.

\section{CANTUESO}

(Lavandula stoechas)

Labiadas

Arbusto cuyas ramas de sección cuadrangular son rojizas y están cubiertas con multitud de pelos blancos. Las hojas son lineares y estrechas de borde entero y de color ceniciento. Las flores forman espigas florales y en su terminación llevan un penacho de brácteas de color violeta o rojizo. El fruto está formado por una especie de nuececillas alargadas. Florece en primavera y se cría en colinas, matorrales y lugares secos y abiertos. Su aceite se usa en perfumería y sus inflorescencias contra afecciones de las vías respiratorias.

$\mathrm{DL}$ : cantueso (BEC); cantrojo (B); cantuešo (CyV).

OV: cantrojo (Bierzo), G. Rey; cantruešo (Cabrera), Casado; galanita (Béjar), Marcos; cantueso (Tenerife), Alvar; id. (Cuenca), Calero.

\section{CARPAZA}

(Cistus psilosepalus) 


\section{Cistáceas}

Matilla de baja altura con ramas y hojas vellosas, oval lanceoladas y sin pedúnculo. Las flores son blancas en grupos terminales con brácteas provistas de grandes pelos. Fruto también velloso en cápsulas abrideras por valvas. Florece en abril y se cría en matorrales bajos, lugares secos y pedregosos.

DL: carpaza y carpanza/-o (B); carpizu (MR).

OV: carpazus 'urce más pequeña' y carpizu 'planta de monte parecida al brezo o urce pequeña (Sisterna), J. A. Fernández.

\section{CARQUESA}

(Genistella tridentata)

Leguminosa

Arbusto leñoso y ramificado, resistente al frío; carece normalmente de hojas y sus tallos están provistos de alas anchas formando tres prominencias o dientes. Las flores, amariposadas y formando hacecillos terminales son de color amarillo o anaranjado. El fruto es una legumbre peluda con varias semillas. Florece en abril y se cría en suelos desprovistos de cal y forma parte de matorrales tras la desaparición del roble. Se utiliza tradicionalmente contra la tos, la gripe y la pulmonía.

$\mathrm{DL}$ : carquesa y carquisa (BEC), (MyA); carqueisa y carqueŝa (B); carqueja y carcaja (BEC); carqueišia/-al (ML), (CyV), (MyA), (B).

OV: carqueix"a (bable occid.), Acevedo; carqueixa 'carquexia', planta medicinal; id. en gallego (Maragatería y A), Alonso Garrote; carqueja (Santander), García Lomas; carqueisa 'carquexa. De las ramas hacen las mujeres estropajos (bable occid.), Rodríguez-Castellano; id. (Sisterna), J. A. Fernández; Acad. carquesa 'arbusto' y carquesia 'mata'.

\section{CASTAÑo}

(Castanea sativa)

\section{Fagáceas}

Árbol de tronco grueso y corteza fina pardo-oliva, hojas enteras y borde aserrados. Las flores amarillentas y estrechas nacen en espigas que brotan de la axila de la hoja. El fruto, la castaña, se agrupa en el interior de una cápsula erizada de espinas; secas, se denominan castañas pilongas. Florece en mayo y se cría en suelos frescos y húmedos. La madera se usa en carpintería, la corteza para curtir pieles y en medicina popular para detener toda clase de flujos e inflamaciones.

$\mathrm{DL}$ : castaño (B), (BEC), (CyV), (ML); castañal (ML), (CyV), (MyA); castaño bravo (BEC), (B); castañal bravo (MyA), (BEC), castañeiro (B). 
OV: castañeiro (bable occid.); Acevedo; castañar/-l (Santander), García Lomas; id. (Cabranes), Canellada; id. (Babia y L.), Álvarez; id. (Colunga), Vigón; id. (bable occid.), Rodríguez-Castellano; id. (Sisterna), J. A. Fernández; id. (Cabrales), Fernández-Cañedo; id. (Cabo Peñas), Díaz; catañera (Bielsa), Badía; castañero (Lena), Neira; id. (Villena), torreblanca; castañu (Pas), Penny; castañalera o castañeira 'castañar' (Santander), García Lomas; castañeu 'terreno poblado de castaños' (Colunga), Vigón; id. (Cabrales), Fernández-Cañedo; id. (Cabo Peñas), Díaz. Se aplica también al árbol aislado. Sinónimo de castañar. Castaño en ALA, 397; ALEANR, III, *354; ALEICAN, I, 257; ALES, 206.

\section{CEREZO}

(Prunus avium)

Rosáceas

Árbol de corteza lisa y pardo rojiza, hojas ovales y dentadas. Flores blancas pedunculadas formando hacecillos semejantes a umbelas. El fruto, la cereza, es globular rojo oscuro o negruzco, de sabor dulce. Florece en marzo y se cría en setos, bosques y huertos, pues es muy cultivado por sus frutos comestibles. Los rabitos son diuréticos y con las cerezas se preparan aguardientes y mermeladas; se recomienda contra la gastritis y obesidad.

DL: cerezal (MR), (CyV), (ML), (BEC), (MyA); cerezo (B), (ML), (BEC), (MR); cerezo bravo (B); cerezo silvestre (MR); cereizal y zreisal (CyV); cereixal (B); zrisal y zrizal (ML).

OV: creisal 'cerezo' (Sanabria), Krüger; cereiceira, cereixal, cereiẍeira,

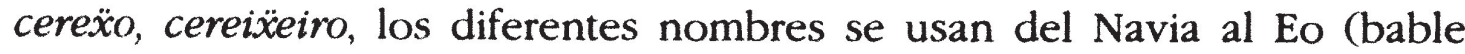
occid.), Acevedo; cerezal (Santander); García Lomas; id. (Cabranes), Canellada; id. (Lena), Neira; id. (Cabo Peñas), Díaz; id. (Maragatería y A) Alonso Garrote; id. (Tejerina), Villarroel; id. (Colunga), Vigón; cirasera (Bielsa), Badía; zreizal, zreišal y mourán 'cerezo que produce cerezas moradas' (bable occid.), Rodríguez-Castellano; cireizal (Sisterna), J. A. Fernández; sirera y sirerera (A. Ribagorza), Haensch; zreizal (Cabo Peñas), Díaz; seresero (Orihuela), Guillén; cerecero (Villena), Torreblanca; zrisal y cerezal (Cabrera), Casado; cereixal (Bierzo), García Rey; zrizal (La Lomba), Morán; zreisal (Valle Gordo), Rubio. Y el fruto: creixa (bable occid.), Acevedo; cereiza, cireiza y zriza (bable occid.), Rodríguez-Castellano; seresa, sirera (A. Ribagorza), Haensch; zreiza (La Lomba), Morán; cerezo en ALA, 433; ALC, 477; ALEANR, III, 378.

\section{CIPRES}

(Cupressus sempervirens) 


\section{Cupresáceas}

Árbol verde todo el año, de copa muy alargada y estrecha, con corteza agrietada y estriada; las hojas son punzantes y aciculares. Su fruto es semejante a una nuez verde que se hace leñosa para liberar las semillas. Florece en marzo, se cría en climas templados, y crece espontáneo en colinas; se ha cultivado como ornamental y funerario, siendo característico de claustros y cementerios.

DL: alciprés (B); ciprés (BEC), (ML), (B) y (MyA).

OV: alciprés y arciprés (Rioja), Goicoechea; acipré (Coria), Cummins; alsiprés y arsiprés (Orihuela), Guillén; aciprés y arciprés (Villena), Torreblanca.

\section{Ciruelo}

(Prunus domestica)

Rosáceas

Arbolillo con ramas grisáceas y frecuentemente espinosas; hojas aovadas y margen aserrado. Las flores son blancas y el fruto es una drupa, la ciruela, cultivada o silvestre, globular y con hueso rugoso. Su color varía. Florece en abril y se cría en suelos frescos, huertos y vegas. Posee propiedades laxantes y por fermentación se preparan bebidas alcohólicas.

$\mathrm{DL}$ ciruelo (BEC), (ML), (B), (CyV), (MyA); cirolero (MR), (B); cirujal y cirolal (MR), cirolar (CyV), (BEC), (B); cirular, ciruelar, cirojal, cirolillo (BEC). Var. silvestres o subespecies: cascabelillar y cascabelillo, entreverde y avacena (BEC); nisal y el fruto nisal-o 'ciruela pequeña y brava' (ML), (B); prunal y el fruto pruno o ciruela salvaje (ML), (MR) y brunillo (BEC).

OV: meixena o mei ena 'ciruelo' (Sanabria), Krüger; ciroleiro úsase como cirola; en la parte central ciruelar (bable occid.), Acevedo; cerojal 'ciruelo', ceroja 'ciruela' y ciruelal 'cirolar' (Santander), García Lomas; cerigüelar 'ciruelo' y cerigüela o cirigüela 'ciruela' (Cabranes), Canellada; cirgoller (Bielsa), Badía; cirgüeyal 'ciruelo', cirgüeyo 'ciruela morada' y piumu 'ciruela silvestre' (A. Aller), Rodríguez-Castellano; cirgüello (Aragüés), González Guzmán; la ciruela 'el ciruelo' (Lena), Neira; ciruelar (Colunga), Vigón; cirular y cirulera (bable occid.), Rodríguez-Castellano; cirgüelera 'ciruelo' y cirgüela 'ciruela' (Tenerife), Alvar; cirolero 'ciruelo que da prunos' (Sajambre), Fernández González; peruné y pruné 'ciruelo', perin y prun 'ciruela' (A. Ribagorza), Haensch; cirgouyu y ciruolar 'ciruelo', cirguola 'ciruela', Fernández-Cañedo; cerigüela 'ciruela' (Cabo Peñas), Díaz; prunero 'ciruelo' (Orihuela), Guillén; cirolar (Maragatería 
y A), Alonso Garrote; cirojal y cirujal (Villacidayo), Millán; cirojal (Tejerina), Villarroel. Variedad: nisal, los frutos nisos 'son de color morado y agrio' (Lena), Neira; id. (La Lomba), Morán; ñisal árbol que da ñisos 'prunos más dulces que los corrientes'; y nisa 'ciruela pequeña' (Cabranes), Canellada); nisal 'especie de ciruelo' y nisu 'variedad de ciruela pequeña, dulce y de color negro', en la región occidental nisa (Colunga), Vigón; nisal que da nisas 'ciruela pequeña, redonda y verdosa', la silvestre se llama bruno o pruno y pruyos (bable occid.), Rodríguez-Castellano; prunal 'árbol que da prunos', y pruno 'ciruela salvaje' (Sajambre), Fernández González; nisar 'ciruelo silvestre', prunal 'especie de ciruelo' y prunu 'especie de ciruela' (Cabrales), FernándezCañedo; nisal 'ciruelo', nixo 'ciruela' (Valle Gordo), Rubio; cascabelillo (S p. insititia) 'variedad de ciruela peque-ña y esférica, de color verde o morado' (Maragatería y A), Alonso Garrote; id. y cascabelillar 'ciruelo que da cascabelillos' (Villacidayo), Millán.

\section{CODESO}

(Adenocarpus complicatus)

Leguminosas

Arbusto con ramas estriadas, hojas trifoliadas y hojuelas lanceoladas y cubiertas de pelillos sedosos. Las flores amarillo anaranjadas están dispuestas en racimos terminales. El fruto comprimido tiene forma arriñonada. Florece en primavera y se cría en matorrales y pedregales.

$\mathrm{DL}$ : codeso (BEC), (MyA), (CyV); codejo (BEC), (MR); cudeso (CyV), (MyA), (BEC); escoba, tudeso, escodojo, codojo (BEC), codocbos, codosio (ML); codoso (ML), (B), (MyA); cudeyo (B); codeiso (CyV).

OV: codox"o 'planta para colocar el día de San Juan en puertas y ventanas, pues tiene la virtud de ahuyentar a las brujas', en Pesos codoxo (bable occid.), Acevedo; codeišo (Cabrera), Casado; codexo (La Lomba), Morán; escodojo 'planta de varas duras y elásticas que se emplea para hacer ramaos, es decir, escobas para barrer la era'; codojo 'escoba de varillas fuertes' (Villacidayo), Millán; cudoxo 'arbusto silvestre parecido a la retama' (bable occid.), Rodríguez-Castellano.

En Mataleón la escoba es de aujera o de mota y en Villamandos llaman escoba a la (odont it is verna) que es escrofulariácea; cuando es de mayor tamaño escoba de ripia y al fin escoba de balea; crece en lugares próximos al río Esla.

\section{CORNEJO}

(Cornus sanguinea) 


\section{Cornáceas}

Arbusto con ramas rojizas y hojas enteras, aovadas, opuestas y pecioladas; pálidas por el envés y de nervios prominentes y con ramilletes formados por flores blancas. Fruto negro, globular y carnoso. Florece a partir de mayo y se cría en setos, matorrales y prados viejos. Sus ramas flexibles se usan en cestería, y de sus frutos se obtiene aceite utilizado para hacer jabones.

$\mathrm{DL}$ : sanguño (MyA); sanguiño (CyV); cornejo y sanguino (BEC).

OV: cornabuelo 'corneo sanguíneo. Arbusto cuya madera, dura y elástica, se emplea para mangos de herramientas, aros y bieldos', a su fruto se le llama matacán (Campóo),García Lomas; albellanino (Andal.), V. Alcalá; sanguinu (El Rebollar), Iglesias.

\section{CORNICABRA}

( $P$ is t a c i a terebinthus)

Anacardiáceas

Arbusto de tallos resinosos y aromáticos y hojas opuestas con foliolos ovales. Flores en racimos ramificados de color púrpura. El fruto es rojo y al madurar pardo. Florece a partir de abril y se cría en matorrales, colinas y lugares rocosos. Posee un látex de olor agradable empleado en el tratamiento del cáncer.

DL: cornicabra y cornacabra (BEC), (MR); escuernacabra (ML), (B); jedisco (MR).

OV: quemaculo 'cornicabra. Se llama así porque de este arbusto cortaban las varas de castigo los maestros de escuela; escuernacabras, id. (vid. Descuernacabras; también terebinto, higuera silvestre) (Santander), García Lomas; corneta 'cornicabra, arbusto y baya de cornicabra que se emplea como sahumerio' (Andal.), Alcalá V.; cornicabra 'arbustillo que nace en la misma peña' y también jedisco (Sajambre), Fernández González; escuernacabra (Valle Gordo), Rubio; cornicabro (Cuenca), Calero.

\section{COSCOJA}

(Quercus coccifera)

Fagáceas

Arbusto perennifolio, con hojas parecidas al acebo, ovales, con el margen espinoso y glabras por el envés. El fruto, la bellota, está en una cápsula con escamas espinosas. Florece en abril y se cría en matorrales y laderas pedregosas y secas. Su corteza es rica en taninos y se usa para curtir. 
DL: coscoja, chaparro, carrasca (BEC); cuzcochu (ML); carcojal-o, carcoxa (MR).

OV: cuzcocbu 'coscojo' (Babia y L.), Álvarez; chabarrasca 'mata de coscoja de uno a dos años'; chabascal/-r 'coscojal' (Andal.), Alcalá, V., carcoxa y carcoxo 'mata enana de haya, de roble o el roble enano' (Sajambre), Fernández González; coscojo 'coscoja', 'carrasca' (Rioja), Goicoechea; carcoja 'mata pequeña y espesa que forma los bardales' (Montaña), González; coscoja o chaparro (Cuenca), Calero.

\section{CHOPO}

(Populus nigra)

Salicáceas

Árbol de tronco grueso y corteza agrietada con numerosos retoños y abultamientos; hojas con margen aserrado estrechándose hacia el ápi-ce. Flores agrupadas en ametos colgantes. Florece a partir de marzo y se cría en sotos, riberas de ríos y caminos. Se presentan muchos ejemplares como 'chopas' de poca altura. Se utilizan sus yemas en ungüento muy popular.

DL: chopo (todos); chopu y choupo/-a (ML).

OV: chopru (Sanabria), Krüger; chopa 'el árbol llamado chopo cuando se le ha cortado el tronco a unos tres metros de altura sobre el terre-no para que broten muchas ramas. Cuando éstas llegan a ser suficientemente largas, se entresacan para utilizarlas como plantones' (Maragatería y A), Alonso Garrote; chopa 'chopo, álamo negro' (La Ribera), Llorente; id. (Valle Gordo), Rubio; emplanto 'chopo recién plantado' (Villacidayo), Millán; povisa 'flor del chopo' (Bierzo), García Rey; choupo (La Lomba), Morán; id. (bable occid.), Rodríguez-Castellano; id. (Babia y L.), Álvarez González; chopo (A. Ribagorza), Haensch; id. (Cuenca), Calero; temblero 'chopo' (Aragüés), González Guzmán; chopo (Álamo), en ALEA, II, 377; ALEANR, III, *399.

\section{DURAZNILLO}

( $\mathrm{Viburnum}$ tinus)

Caprifoliáceas

Arbusto perennifolio con hojas coriáceas, ovales y enteras. Flores de color rosado, dispuestas en ramilletes y vástagos rojizos. El fruto es de color azul negro brillante cuando está maduro. Florece en febrero y se cría en bosques, espesuras y lugares pedregosos.

$\mathrm{DL}$ : durillo (BEC).

OV: duraznilla, en ALEA, II, *354; durazno, ALEANR, III, 361.

\section{ENABIO}


(Genista legionensis)

Leguminosas

Arbusto achaparrado con hojas lanceoladas, lampiñas por arriba $y$ vellosas por abajo. Las flores de color amarillo nacen de la axila de las brácteas agrupándose en racimos. El fruto es una legumbre oblonga con varias semillas. Esta especie cantábrica florece en abril y se cría en lugares montañosos. Es utilizada para aromatizar.

$\mathrm{DL}$ : enabio (BEC); anabio y anao (MR).

OV: anabio y anao (Sajambre), Fernández González.

\section{ENCINA}

(Quercus rotundifolia)

Fagáceas

Árbol con corteza cenicienta y resquebrajada, hojas ovales y redondeadas de borde entero o con dientes, coriáceas. Sus flores amarillentas crecen en racimos, y su fruto es una bellota ovoide en cuya base hay una cápsula hemisférica de color parduzco. Florece en abril y se cría en laderas y setos soportando climas duros. Las bellotas son comestibles, y las agallas y corteza se han empleado para curtir pieles, y su madera compacta y dura, en carpintería.

DL: encina (BEC), (MyA), (CyV), (B); encino (B); ancina (MyA), (CyV), (BEC); chaparro, bellotero, carrasco (BEC); sardón, sardonal (MyA), (CyV); xardón, jardón, jardonal, carrasquera (B). Cuando es joven: encineta/-o, ramasco, encina nueva (BEC).

OV: carrascu 'carrasca' (Sanabria), Krüger; sardón 'encina pequeña' (Cabrera), Casado; id., 'mata achaparrada de encina' (Maragatería y A), Alonso Garrote; carrasquera 'mata de carrascos', jardón y xardón 'sardón' e incinal 'encinar', jardonal, sardonera y xardonal 'sardonal' (Bierzo), García Rey; carrasca 'encina joven' (Santander), García Lomas; carrasca 'encina' (Bielsa), Badía; id. (A. Ribagorza), Haensch; carrasco 'encina' (Aliste), Baz; id. 'encina muy joven' (Sayago), Borrego; Chabasco 'chaparrera muy apretada y de baja altura', chabasquera, chaparrera, chaparreta 'mata del chaparro, carrasca' (Andal.), Alcalá, V.; carrapito 'encina pequeña' (Aliste), Baz; ancina (bable occid.), Rodríguez-Castellano; id. e incina (Pas), Penny; id. (Coria), Cummins; id. (Sayago), Borrego; carrascu 'encina baja' (Pas), Penny; chavasco 'encina pequeña' (Anguiano), Echaide; carrasquero (Sayago), Borrego; el encinar o carrascal es el charrascal (Andal), Alcalá, V.; carroscal (Pas), Penny; chavascal (Anguiano), Echaide; saronal (Maragatería y A), Alonso Garrote; encina en ALA, 57; ALC, I, 73; ALEA, II, 367; ALEANR, III, 386; ALVA, 71; encina 
joven en ALEA, II, 368; ALEANR, III, 388; ALES, 230; encina silvestre, ALEA, II, *367; ALEANR, III, 387.

\section{ENDRINO}

(Prunus spinosa)

Rosáceas

Arbusto espinoso de ramas cortas y retorcidas con corteza oscura y hojas aovadas con márgenes dentados. Flores axilares de color blanco o amarillento. El fruto, el endrino, es una pequeña ciruela que contiene un huesecillo arrugado. Florece en marzo y se cría en suelos secos y soleados. Con sus frutos se hacen jarabes y se utiliza en la fabricación de licores; son astringentes y sus flores laxantes.

DL: endrino, bruno, bruño, brunal (BEC); andrinal y andrino (MR); abrunal, espino de abrunos, andrino, bruño, endrina, abruñero (B); prunal, apruno, abruñal, andrino (MyA); abranal, espino (CyV); espino peronal, espino prunal, espino de perunos, peruno (ML); el fruto se denomina: abruno (B), pruno, andrino, peruno (ML); bruno, andrín (MR); bruno, embruno, abruno, andrino (BEC).

OV: La ciruela silvestre tiene múltiples denominaciones además de las citadas en el (Prunus domestica). Abruñeiro 'árbol que produce abruños'. El abruño o bruño es el bruno, ciruela negra. En Oviedo prunos y andrinos; ameix "eira 'endrino o ciruelo' (bable occid.), Acevedo; abrunal 'planta del abruno, y fruta del espino' (Bierzo), García Rey; pruno o prunillo 'ciruelo silvestre y su fruto'; y brunera, árbol y fruto del 'pruno'; también ragaña o regañona, 'endrina', pruna u otra fruta que por ser ácida hace 'arremellar' o 'arregañar' los dientes al comerla (Santander), García Lomas; andrinal 'endrino', andrín 'fruto' y prunal 'árbol de prunos'; cagarriones, 'prunos pequeños, azules o negros de sabor poco agradable'; ñuciles, 'prunos azules, pequeños y alargados', pirulinos, 'prunos pequeños, encarnados, muy sabrosos' (Cabranes), Canellada; indrina, 'endrina, fruto del endrino' (Andal.), Alcalá, V.; cabarrón 'variedad de pruno pequeño, duro y muy agrio; prunal 'especie de ciruelo', prunu o andrín 'variedad de ciruela de color negro' y prunuandrín 'fruto del endrino' (Colunga), Vigón; pirucbecbo (Lena), Neira; andrinero 'endrino' y andrín 'fruto' (bable occid.), Rodríguez-Castellano; prunal ‘árbol que da prunos' y prunu 'ciruela salvaje' (Babia y L.), Álvarez González; andrinal 'endrino', árbol silvestre y andrín 'fruto del andrinal' (Sajambre), Fernández González; abrín, pl. abruís 'bruno' (Sisterna), J. A. Fernández; andrinal (Tejerina), Villarroel; andrinal 'arbusto que da andrinos' y andrino 'fruto de hueso pequeño y de sabor agrio que al madurar adquiere un color morado' y brunal 'ciruelo que da brunos' y 
bruno 'ciruela morada, pero más grande que el cascabelillo, que también lo es' (Villacidayo), Millán; espinau y priñoné 'espino' (prunus spinosa); priñón y priño 'endrina' (A. Ribagorza), Haensch; androla 'endrina, fruto del endrino' y marañón 'fruto del endrino o ciruelo silvestre' (Rioja), Goicoechea; endrinu 'endrino' (Cabrales), Fernández-Cañedo; andrinal 'endrino', andrin 'fruto del endrino' y escayu que da frutos negros muy amargos (Cabo Peñas), Díaz; id. (Bureba), González Ollé; andrinu, ispinu, ispinu de andrinas 'endrino' (Pas), Penny; bruñera 'endrino', 'ciruelo silvestre, cuyo fruto es el bruño que es una especie de ciruela negra o de color morado muy oscuro, y de forma ovoidal y también, árbol que los produce' (Béjar), Marcos; bruño, bruñal, ciruelo silvestre 'endrino' (Sayago), Borrego; abruñu 'ciruela' (El Rebollar), Iglesias; andrina en ALA, 116; ALEC, I, 138; ALEA, II, *359; ALEANR, III, 371; ALES, 220; ALVA, 136; y endrino en ALEA, II, 359; ALEANR, III, 370; ALES, 219.

\section{ENEBRO}

(Juniperus communis)

Cupresáceas

Arbusto perennifolio espinoso, con hojas puntiagudas, puntas espinosas en verticilos, con una banda central blanca en la parte superior. Las flores, pardorrojizas, son masculinas y femeninas y crecen en plantas separadas. El fruto es una baya, verde al principio y negra azulada cuando madura; contiene la semilla y un aceite esencial aromático. Florece en mayo y se cría en las montañas entre pinos, robles y brezales. Es antiséptico y se ha utilizado contra las afecciones renales y bronquiales.

$\mathrm{DL}$ : enebro (BEC), (ML), (MR); enebrio (BEC), (ML); eneblio (BEC); nebreria/mebrera (CyV).

Una variedad es el Juniperus oxycedrus cuyas hojas son también puntiagudas y lineares con dos líneas blancas en el envés; produce unos frutos amarillo verdosos que se vuelven negros al madurar. Florece en mayo y se cría en todo tipo de suelos. Su aceite se usa en medicina contra enfermedades de la piel. Se le llama nieblo y cimbrio o cimbro (B).

OV: enbambri y enhembri 'enebro' (La Ribera), Llorente; chinebro (Aragüés), González Guzmán; nebro (Sayago), Borrego; buto y el fruto buta (Cuenca), Calero.

\section{ENEBRO RASTRERO}


(Juniperus communis sp. alpina) Cupresáceas

Arbusto semejante al enebro común, de poca altura, achaparrado debido al clima frío que tiene que soportar, pues coloniza zonas de alta montaña. Sus hojas son más cortas y estrechas en la punta y curvadas. Con sus bayas puede también aromatizarse la ginebra; estas nebrinas metidas en aguardiente se utilizaban como digestivas y sudoríficas.

DL: gorbizu, gorbizo y gorbicio (ML); gurbiezo (MR).

OV: gurbizu 'planta parecida al árgoma, más baja y más abierta' (Babia y L), Álvarez; gurbizu, planta parecida a la jara, puede confundirse con la sabina rastrera ( $\mathrm{J}$ u i perus s a bin a) llamada gorbizo liso; gurbiezo 'arbusto parecido al brezo' (Sajambre), Fernández González.

\section{ESCARAMUJO}

(Rosa canina)

Rosáceas

Rosal silvestre o arbusto sarmentoso con espinas fuertes y curvadas; hojas aovadas o elípticas y aserradas en los bordes. Flores blancas, rosadas y encarnadas; el fruto cuando madura es una baya roja, carnosa y dura. Florece en mayo y se cría en setos, terraplenes y espesuras. Es una planta muy variable; son comestibles y astringentes y sirve para cortar la diarrea.

DL: espino, rosal bravo, gavanza, rosal, espinu garbanceiru, garvanzal (ML); agavanzo/-a, gavanza, garvancera (B); espino de agabanzo (CyV); rosal (MyA); pinchaculos, garbancera, rosal montisco, garamito (MR); agavanzo, rosal trepador, rosal bravo, agavanza, zarza, zarza de garabita, zarza revilva, rosal, revilva, legumbres, agavanzal (BEC). Y el fruto es el picaculos y tapaculos, avaganza, agavanza, aveganza (BEC); garamito (MR); garbanzu, garbanzo (ML).

OV: roseira 'rosal' (bable occid.), Acevedo; agabanza 'escaramujo, empleáse para cercar prados, huertos y viñas' (Bierzo), García Rey; id. (Maragatería y A), Alonso Garrote; id. (Villacidayo), Millán; zarza (Maragatería y A.), Alonso Garrote; id. (Tejerina), Villarroel; id. (Cuenca), Calero; gavilancero (A. Aller), Rodríguez-Castellano; garvancera (Sayago); garbancera (Sajambre), Fernández González; garbanzal (La Lomba), Morán; id. (Valle Gordo), Rubio; id. (bable occid.), Rodríguez-Castellano; subiadal (Maragatería), Alonso Garrote; espinu garbanceiru (Babia y L), Alvarez Guzmán; gabanzal (Bierzo), García Rey; calambrujo (Rioja), Goicoechea; calambrojal (Santander), García Lomas; id. (Pas), Penny; escalambrujo 'escaramujo, rosal y su fruto' (Rioja), Goicoechea; corales (Rioja), Goicoechea; taramujo (Córdoba), Alcalá V.; escaramujera (Cuenca), Calero; garameta y rosal de la raposa (bable occid.), Rodríguez-Cas- 
tellano; rosal de libra (Tenerife), Alvar; garrabera (A. Ribagorza), Haensch; catapul (Bureba), González-Ollé; rosal del diablu (Cabo Peñas), Díaz; zarza de calambrojas e ispinu (Pas), Penny; caramullero (Villena), Torreblanca.

El fruto es el garbanzo (Valle Gordo), Rubio; id. (bable occid.), Rodríguez-Castellano, garamito (Montaña), González F.; id. (Sajambre), Fernández González; garbanzu (Babia y L), Álvarez Guzmán; bailarote y bailarín (Colunga), Vigón; calambrojo y bailarín (Santander), García Lomas; tomatico/-illo (Andal.), Alcalá, V.; mazacoral (A. Aller), RodríguezCastellano; picaculo (bable occid.), Rodríguez-Castellano; garrabón y garrabó (A. Ribagorza), Haensch; calambruju, calambroja, iscalambruju y picaculu (Pas), Penny; escarambujos (La Roda), Chacón; balbaretas (Sayago), Borrego; escaramujo en ALEA, II, 310; ALEANR, III, 296; ALES, 164.

44. ESCOBA BLANCA

(Cytisus miltiflorus)

Leguminosas

Arbusto con ramas angulosas y flexibles; hojas dentadas y trifolia-das en la parte inferior de la rama, con numerosas flores blancas formando largas inflorescencias. Fruto comprimido con varias semillas negruzcas. Florece en abril y se cría en matorrales y suelos pobres. Hay varias especies y es difícil distinguirlas, por eso, el nombre popular varía.

DL: escoba (ML) y (BEC); escoba albar (MR); escoba de flor blanca (B); escoba blanca (MyA).

\section{ESCOBA NEGRA}

(Cy tisus scoparius)

Leguminosas

Arbusto con ramas flexibles y hojas lanceoladas. Flores amarillas, amariposadas y olorosas. Fruto comprimido y alargado, velloso en el margen. Florece en abril y se cría formando parte de matorrales y monte bajo. Se ha utilizado para hacer escobas y la corteza para curtir. Es una planta muy tóxica. Sus flores se utilizan para tratar afecciones de bazo, hígado y como estimulante de las fibras del útero.

DL: escoba (BEC), (B), (ML), (MR), (CyV), (MyA); escoba de flor amarilla (B), (ML); escoba amarilla (MyA); retama, retama negra y retama morisca (ML).

OV: escoba y también barredoira 'planta verde de la familia de las leguminosas, bastante alta, propia para hacer escobas con que barrer el interior de las casas' (Babia y L), Álvarez González; escobonera 'retama' 
(Andal.), Alcalá V.; id. (Rioja), Goicoechea; morisca 'se aplica a una variedad de la retama, de hojas un poco más oscuras que la ordinaria'; chinastra y chinestra 'retama, iniesta' (G e n ista s coparius) (A. Ribagorza), Haensch.

\section{ESPLIEGO/LAVANDA}

(Lavandula spica L. lat ifolia) Labiadas

Arbustillo muy aromático, ramificado y leñoso en la base; hojas opuestas, lineales, con el margen enrollado. Las pequeñas flores violáceas o azules forman largas espigas. Florece a partir de junio y se cría en laderas, colinas y lugares soleados. Cultivado como ornamental por sus flores y follaje de los que se extrae un aceite esencial utilizado en perfumería. Se usa para combatir cólicos y el alcohol de espliego contra el reumatismo. La (L. la tifolia) es mayor y con hojas más anchas; su aceite es menos dulce, similar al alcanfor.

DL: espliego, lavanda (BEC).

OV: espicol 'espliego' (Jaca), Alvar; esplico (Bielsa), Badía; jucema y lucema 'alhucema, espliego' (Andal.); Alcalá V.; espigol (A. Ribagorza), Haensch; albusema (Orihuela), Guillén; espliego (Cuenca), Calero; id. en ALA, 185; ALC, II, 226; ALEA, II, 306; ALEANR, III, 292; ALVA, 225.

\section{FRAMBUESO}

( $\mathrm{R}$ ubus idae u s)

Rosáceas

Planta arbustiva con tallos frecuentemente espinosos. Las hojas son pinnadas con foliolos ovales y márgenes dentados. Las flores forman inflorescencias de color blanco. El fruto, la frambuesa, es rojo y de sabor agradable. Florece en mayo y se cría en pedregales y bosques. Por fermentación se obtiene una bebida alcohólica y se emplea contra el estreñimiento y el reumatismo.

$\mathrm{DL}$ : frambueso (BEC); artimora (MR); altimora (ML); antimora (BEC), (MR).

OV: morapeluda 'frambuesa' (Santander), García Lomas; chordón 'fruto muy parecido a la frambuesa' (Bielsa), Badía; artimora 'frambuesa' (Sajambre), Fernández González; chordón y chordo 'frambuesa' (A. Ribagorza), Haensch; altimora (Valle Gordo), Rubio; id. (Villacidayo), Millán; frambuesa en ALA, 840; ALC, VI, 887; ALEANR, III, *291; ALVA, 874.

\section{FRESNO}

(Fraxinus angustifolia) 
Oleáceas

Árbol grisáceo con corteza fisurada y hojas opuestas por un número importante de foliolos linear-lanceolados con dientes marginales. Flores de color blanquecino y pardo purpúreo formando pequeños racimos colgantes; el fruto es aplastado y seco con una semilla membranosa. Florece en abril y se cría en suelo húmedo, bosques claros y riberas. Muy apreciado en carpintería, posee una corteza tánica, que aunque tóxica se ha utilizado como febrífuga y las hojas se han empleado contra la artritis y la gota.

DL: fresno (todos).

OV: frédenu 'fresno' (Sanabria), Krüger; frašin y frasno (Jaca), Alvar; fleixin y freixén (Bielsa), Badía; frenu (A. Aller), Rodríguez-Castellano; frachin y frajín (Aragüés), González Guzmán; frisnu (Lena), Neira; fleisno, fleino y freisnu (bable occid.), Rodríguez-Castellano; freiše, freiš (A. Ribagorza), Haensch; fresno (Cabo Peñas), Díaz: id. (Aliste), Baz; friznu pl. freznus 'fresno', ujulobu 'fresno montisco' (Pas), Penny; freno (Orihuela), Guillén; fresno en ALEA, VI, 1957; ALEANR, III, 399; ALES, 980.

\section{GATUÑ̃}

\section{(Ononis spinos a)}

\section{Leguminosas}

Planta arbustiva de base leñosa con tallos espinosos; hojas perennes, trifoliadas y frecuentemente simples, las superiores; los foliolos son ovales y dentados. Las flores axilares rojizas o blancas. el fruto suele ser velloso de una semilla. Florece a partir de abril y se cría en lugares secos, herbosos y en cunetas.

DL: gatita, gatiña, gatina (CyV); uña gato, gatiña (MyA); gatuña (B); uña de gavilán, gatuña, gatiña (BEC).

OV: gatiña 'hierba gatuna, abrojo que infecta algunas tierras de labor y produce dolorosas heridas a los segadores' (Maragatería y A.), Alonso Garrote; id. (Bierzo), García Rey; tiragüé 'gatuña' (Colunga), Vigón; bolomaga y esbolomaga (A. Ribagorza), Haensch; gatuna, gatuña, uña de gato, anonis, detienebuey 'es planta diurética' (Béjar), Marcos; gatuña en ALEA, II, 292; ALEANR, II, 279.

\section{GAYOBA}

(Arctostaphylos uva-ursi)

\section{Ericáceas}

Mata rastrera o subarbusto con hojas coriáceas, ovaladas y enteras; flores blancas o rosadas dispuestas en racimos terminales; el fruto es una baya roja comestible. Florece en primavera y se cría en bosques y 
suelos ricos en humus. Sus hojas son tánicas y se obtiene de ella una bebida refrescante; se ha utilizado como desinfectante de vías urinarias.

DL: fabayoba (MyA); agabuja (ML); agayuba, gayuba y fabayoga (BEC).

OV: manzaneta 'gayuba' (A rbutus uva-ursi) (Santander), García Lomas; bizcoba, gapa y gayuca (Cornago); 'gayuba' (Rioja), Goicoechea; gayuba, gayubilla y gayumina (Cuenca), Calero.

\section{GROSELLERO}

( $\mathrm{R}$ ibes rubrum)

Grosulariáceas

Arbusto sin espinas, de hojas alternas, acorazonadas y divididas en lóbulos con márgenes enteros. Las flores de color verde amarillento se agrupan en racimos colgantes. El fruto, la grosella, es globular de color rojo brillante y en ocasiones de color blanco verdoso. Florece en primavera y en estado silvestre se cría en setos y zonas boscosas húmedas. Es refrescante y diurético. Se emplea para combatir inflamaciones gastrointestinales y diversas afecciones cutáneas.

$\mathrm{DL}$ : grosellero y grosellero bravo (BEC).

OV: brus ^elar 'grosellero' (Lena), Neira; grosella en ALEANR, III, *300.

\section{GUINDO}

(Prunus cerasus)

Rosáceas

Árbol de corteza gaisácea y resquebrajada, hojas lustrosas y acuminadas, más pequeñas que las del cerezo, y de rabillo más corto; el fruto, la guinda, es de color rojo brillante y de sabor agridulce. Florece en abril y se cría en suelos frescos y profundos en las zonas de regadío y en montañas, ejemplares aislados. Con sus frutos se obtiene aguardiente de guinda.

DL: guindo (ML), (MyA), (BEC); quindal (BEC), (MR), (B).

OV: guindal (Maragatería y A.), Alonso Garrote; id. 'árbol de guindal o guindo, con la diferencia de adoptar el género femenino (la guindal, una guindal)' (Tejerina), Villarroel; montesina 'guindal silvestre' (La Ribera), Llorente; id., 'árbol que da guindas' (A. Aller), Rodríguez-Castellano, id. (Colunga), Vigón; id. (Villacidayo), Millán; guindeira, guindal y guindar (bable occid.), Rodríguez-Castellano.

\section{HAYA}


(Fagus sylvatica)

Fagáceas

Árbol grisáceo con corteza lisa y hojas alternas de borde dentado y ovaladas. Las flores se disponen en inflorescencias globosas colgando de un peciolo. El fruto, el hayuco, está en una cápsula erizada de espinas no punzantes, se comen tostados y son utilizados para pienso. Florece en abril y se cría en laderas de montañas, suelos frescos y climas suaves. Se utilizaba la brea obtenida de la combustión para combatir la tuberculosis, y las hojas mascadas, para curar heridas de la boca.

DL: haya (BEC), (MyA), (MR), (B); faya (ML); zaya (B); caxiga haya joven', jaya y jayuco 'haya pequeña' (MR); el fruto es el hayuco o jayuco (MR).

OV: fayeu 'hayedo' (Cabranes), Canellada; fabarrina 'haya' (Jaca), Alvar; fau (Bielsa), Badía; faya 'haya'; fauco 'fruto' y pindal de fayas 'hayedo' (A. Aller), Rodríguez-Castellano; faya (Babia y L), Álvarez Guzmán; fabarrina, fabarra y fabo (Aragüés), González Guzmán; faya 'haya' y fayuco 'hayuco', fayedal 'hayal' (Colunga), Vigón; faya 'haya', fayuco 'hayuco' (bable occid.), Rodríguez-Castellano; jaya 'haya', Ast. general, faga y jayeo 'hayedo', y jayuco 'haya pequeña' y caxiga 'haya que no ha llegado a un normal desarrollo' (Sajambre), Fernández González; faya 'haya' (Sisterna), J. A. Fernández; fau 'haya' y faya 'hayuco' (A. Ribagorza), Haensch; urnija y haya 'haya', urniju 'haya pequeña', bayucus 'fruto' y urnijal, hayal 'hayedo' (Pas), Penny; zagorra 'haya pequeña', fri 'flor y fruto del haya', haido 'hayedo' (Anguiano), Echaide; baya en ALEANR, III, 400.

\section{HIEDRA}

(He dera helix)

Araliáceas

Planta leñosa y trepadora cuya liana se sujeta por un denso sistema de raicillas que nacen del tallo y a veces tapiza el suelo. Hojas variables, con lóbulos triangulares poco marcados y otras veces ovales o rómbicos. Flores en umbelas terminales de color verde amarillento; fruto globular, negro. Florece al final del verano y se cría en bosques, paredes y lugares umbrosos; las hojas se han utilizado para cicatrizar úlceras y los frutos como purgantes.

DL: yedra (MyA), (B), (CyV), (BEC) y (MR); biedra (BEC), (B).

OV: edra (Colunga), Vigón; id. (Cabrales), Fernández-Cañedo; chedra (A. Ribagorza), Haensch; yedra (Pas), Penny); yedra en ALA, 746; ALC, V, 788; ALVA, 779. 


\section{HIGUERA}

(Ficus carica)

\section{Moráceas}

Árbol con corteza gris y lisa, hojas grandes y lobuladas, acorazonadas en la base y pecioladas. Flores pequeñas en un receptáculo y fruto carnoso, el higo, periforme de color verde claro o púrpura. El breval es mayor que la higuera de hojas más grandes y verdes que da higos y brevas. Florece a partir de primavera y se cría en zonas cálidas, malezas y lugares rocosos. Los higos son comestibles, se usan como laxantes y para combatir la tos.

$\mathrm{DL}$ : higuera (BEC), (MyA), (B); figuera, figueira (CyV); higar y jigar (MR); higal y figal (ML), (B); breval (MyA), (BEC).

OV: figueira 'higuera'. En algunos concejos figar y figo 'higo' (bable occid.), Acevedo; bigar o higal e biguero 'higuera', higacal 'higueral' y breval o brevera 'árbol que produce brevas. Es más grande que la higuera, más grueso y de hojas mayores'; brevala y brevalo 'higuera breval' (Santander), García Lomas; figar 'higuera' (Cabranes), Canellada; id. (Lena), Neira; id. (Colunga), Vigón; id. (bable occid.), Rodríguez-Castellano; id. (Sajambre), Fernández González; figal (bable occid. y A. Aller), RodríguezCastellano; id. (Sisterna), J. A. Fernández; id. (Sayago), Borrego; id. (Babia y L), Álvarez; figuera (Bielsa), Badía; id. (Cabrera), Casado; id. (A. Ribagorza), Haensch; jicar (Sajambre), Fernández González; bigar (Cabrales), Fernández-Cañedo; higal (Bierzo), García Rey; id. (Sayago), Borrego; higuera (Coria), Cummins; id. (Sayago), Borrego; jiguera (Tierra de Barros), Murga. El fruto: figa (Bielsa), Badía; id. (bable occid.), Rodríguez-Castellano, id. (A. Ribagorza), Haensch; figu (bable occid.), Rodríguez-Castellano; id. (Colunga), Vigón; id. (Sisterna), J. A. Fernández; id. (Babia y L), Álvarez; figo (bable occid.), Rodríguez-Castellano; id. (Bierzo), García Rey; bigu (Coria), Cummins; biguera en ALEANR, III, *380; ALEICAN, I, *268; ALES, 227.

\section{JAGUARZO}

( $\mathrm{Halimium}$ viscos u $\mathrm{m}$ )

Cistáceas

Arbusto ceniciento con hojas opuestas y uniformemente distribuidas que nacen agrupadas en verticilos, lanceoladas y revueltas en su margen. Flores blancas y vistosas; fruto capsular, puntiagudo y velloso. Florece en marzo y se cría en suelos raquíticos y degradados, casi desprovistos de vegetación.

DL: jagazo y jaguazo, chaguazo, tabaquero y tabaqueiro (MyA); juagazo y jaguarzo (ML). 
OV: jabarzo (Vilches-Jaén); jaguarzo prieto, variedad del jaguarzo, de hoja más oscura (Huelva) y juagarcina, arbusto de la familia del juagarzo o jaguarzo (Andal.), Alcalá V.; jaguarzo o juagarzo (La Lomba), Morán; mantecón 'fruto del juagarzo'; id. 'orobanca, planta' (Valle Gordo), Rubio.

\section{JARA}

(Cistus la danifer)

Cistáceas

Arbusto con vástagos pardorrojizos, de hoja perenne y enfrentadas en forma de lanza. En las sumidades de las ramas echa los vástagos floríferos pegajosos y de olor agradable. Sus flores son grandes y blancas con manchas purpúreas. El fruto es capsular y globoso. Florece en mayo y se cría entre pinares, colinas secas y en general en terrenos sin cal. Se utiliza en perfumería y se preparaba en emplastes para curar hernias y quebraduras.

DL: jara blanca, jara pegajosa y jara negra (BEC); jara (MyA), (ML), (CyV), (BEC); estepa blanca y juaguarzo blanco (ML) y (MyA).

OV: gallarin 'yema de la jara' (La Ribera), Llorente; jara cerval y jara estepa 'arbusto parecido a las que componen su nombre' y trompillo 'baya de la jara que contiene la simiente' (Andal.), V. Alcalá.

\section{JAZMíN}

(Jasminum fruticans)

Oleáceas

Arbusto perennifolio, con tallos angulosos, largos y frágiles, hojas alternas, lanceoladas, duras con el borde entero. Las flores son amarillas o blancas. El fruto es una baya negra y lustrosa. Florece en primavera y se cría asilvestrada en setos, matorrales y pedregales. Sus flores muy aromáticas y olorosas se utilizan en perfumería.

$\mathrm{DL}$ : jazmin (BEC).

OV: ̈̈azmin 'jazmín' us. en muchos concejos de la montaña y en gall. cp. el port. ̈̈asmin (bable occid.), Acevedo; jazminero (Andal.), V. Alcalá.

\section{LAUREL}

(Laurus nobilis)

\section{Lauráceas}

Arbolito de tronco liso, corteza negruzca y de hoja perenne, dura, correosa y lanceolada. Las flores blanco-amarillentas y verdosas nacen en las axilas de las hojas. El fruto es una baya ovoide y negra. Florece en primavera y se cría en setos y espesuras donde puede gozar de un clima 
cálido. Se ha cultivado por sus hojas aromáticas y sus frutos, utilizados en preparaciones farmacéuticas; se considera tónico estomacal.

DL: laurel (BEC), (MyA), (B); llaurer (MyA); laurelal (BEC).

OV: lloureiro y lloreu 'laurel' y horbaga 'especie de bellota que cría el laurel' (bable occid.), Acevedo; llorea 'laurel hembra que tiene flores más abundantes que el macho'; lloreu 'laurel' (Cabranes), Canellada; aurel (A. Aller), Rodríguez-Castellano; id. (Coria), Cummins; id. (Béjar), Marcos; id. (El Rebollar), Iglesias; id. (Pas), Penny; šoriu (Lena), Neira; lloreu, tsoureiro, lloureiro, laureiro y alloru (Colunga), Vigón; tsaurel, tsoureiro, rameira (bable occid.), Rodríguez-Castellano; rameira (Sisterna), J. A. Fernández; orel, lorel (Pas), Penny; laurel en ALA, 906; ALC, VI, 951; ALEICAN, I, 259; ALVA, 934.

\section{MADRESELVA}

(Lonicera periclymenum)

Caprifoliáceas

Arbusto trepador de ramas fuertes y flexibles, con hojas enfrentadas, ovales con margen generalmente entero. Las flores, blanco-amarillentas o teñidas de rosa, de olor agradable, nacen en ramilletes terminales con un largo pedúnculo. El fruto es una baya ovoide, carnosa y roja al madurar. Florece en verano y se cría en matorrales, setos y espesuras. Las hojas y flores se han empleado para curar inflamaciones de garganta.

$\mathrm{DL}$ mariselva y bidaqueira (MR); madreselva (BEC), (B); descuernacabras (MyA), sogüeñas, enreadera silvestre (BEC); bierba enredadera (MyA).

OV: manines de Dios 'madreselva' (Cabranes), Canellada; mariselva y samuso (Rioja), Goicoechea; escuemacabras (La Lomba), Morán; sogüeñas 'madreselvas' (Villacidayo), Millán; marisilva (El Rebollar), Iglesias; madreselva en ALEANR, III, *300.

\section{MADROÑO}

(Arbutus unedo)

Ericáceas

Arbolillo de corteza áspera y escamosa; hojas alternas, elípticas con el margen aserrado. Las flores nacen en racimos colgantes de color blanco, a veces teñidas de color rosa. El fruto es una baya roja y globosa. Florece en otoño y se cría en matorrales, suelos secos y profundos. La corteza se ha utilizado para curtir pieles, $y$ hojas y fruto para hacer licores y para combatir diarreas, disenterías y como antiséptico de las vías urinarias.

$\mathrm{DL}$ : madroño (BEC), (CyV), (B); madroño, madroñera y madroñal (B); albormio (MR); arbedeiro, bérbedo y modroño (B). 
OV: alolicos, borrachino, hérbido, alborto y muérgano 'madroño'; muerganal, abortal o albortal 'sitio poblado de madroños'; y el fruto muérgano y borrachicos o borrachines. Debe este nombre a que comiendo muchos producen dolor de cabeza (bable occid.); Acevedo; madroña 'madroñera', 'arbusto' (Andal.), Alcalá V.; albornial y alborocera 'madroño'; aloboniu 'fruto del madroño' (Colunga), Vigón; arbedeiro, borrachinal, borrachineiro, yérbode, yérbado y el fruto borrachin y muédranos (bable occid.), Rodríguez-Castellano; borracho y borrachino. Fruto del madroñero, muy semejante a la pera, pero mucho más pequeño de sabor amargo. La flor se llama flor de borrachu (Cabo Peñas), Díaz; madroñero (Orihuela), Guillén; madroñera y madroñero (Villena), Torreblanca; madroño en ALC, I, 139; ALEA, II, 309; ALEANR, III, "295; ALES, 162; ALVA, 137.

\section{MAJUELO}

(Crataegus monogyna)

Rosáceas

Arbusto espinoso con pequeñas hojas de lóbulos profundos y márgenes enteros. Flores blancas y olorosas; fruto globoso de color rojo brillante. Florece en mayo y se cría en sotos, ribazos y bordes de tierra de labor. Sus flores se han empleado como tónico cardíaco y los frutos, majolinos, para aliviar la circulación y animar la presión sanguínea, pues son sedantes.

DL: espino (BEC), (MyA), (CyV), (B); espineira, espino blanco, majuelo (B); espinera, espino majueto, espino de majuelo, majuetal, espino majuetero, espino majuelero (MR); espino machugal, espino garaminal, espino graminal, espino picón (ML); espino de amayuelo, amayuelo (CyV); espino blanco, majolino, maulino, maulinar y espino (BEC). Fruto: machuga, gapamina o gramina (ML); maulino (BEC) y (CyV); majueto, mayuela, majueta, garamita (MR).

OV: espin (bable occid.), Acevedo; mayuela 'majuela' (Cabrera), Casado; eriz 'espino' (Jaca), Alvar; espina 'espino blanco' y espinera, machugal, espineiro 'espino blanco' y fruto machuga (bable occid.), Rodríguez-Castellano; espinera y majuelo; fruto mayuela (Sajambre), Fernández González; arañonera y arañoné (A. Ribagorza), Haensch; espino albar 'arbusto, especie de níspero, poblado de espinas, que lleva una frutilla roja que llaman majuela' (Rioja), Goicoechea; hartal 'seto de espinos' (Cabrales), Fernández-Cañedo; guapero 'espino guapero, espino silvestre' (Béjar), Marcos; majuetal 'majuelo' y majueta 'fruto del majuelo' (Tejerina), Villarroel; espino de olor y su fruto es la majueleta o majuela (La Roda); Chacón; ganaperu 'espino albar' (El Rebollar), Iglesias; espino, 
majuelo y espino albar (Cuenca), Calero; espinera (Colunga), Vigón; majoleta en ALEA, II, 313; ALEANR, III, 299; ALES, 167; y majoleto en ALEA, II, 311; ALEANR, III, 298; ALES, 166.

\section{MANZANO}

(Malus domestica)

Rosáceas

Árbol con ramas espinosas generalmente y ramillas sin vello. Hojas lampiñas por ambas caras como el silvestre (M. s y lvest ris) y elípticas. Flores blancas o rosadas; el fruto, la manzana, cuando está verde es ácido. Florece en abril y se cría en vegas, claros de monte, setos. Hay numerosas variedades y se distingue por la forma del fruto. Se emplea como laxante y combate los desarreglos intestinales.

$\mathrm{DL}$ : manzano (todos); manzanal (ML), (BEC), (CyV), (MyA); carozal y manzano bravo 'manzano silvestre' (B) y fruto carveza y manzana brava (B), (ML) y (MyA); manzana y manzanal montisco (MR).

OV: maceiro y el fruto mazá (bable occid.), Acevedo; manzanal y el fruto mazana (MyA), Alonso Garrote; id. (Babia y L.), Álvarez Guzmán; id. (Bierzo), García Rey; carueza 'manzana silvestre que es brava, pequeña y propia de invierno; aplícase también al árbol que la produce' (Valle Gordo), Rubio; maillo o maello 'maguillo (m a lus a c e rba) o manzano silvestre, mailas o maellas 'manzanas silvestres', fruto del maguillo o maillo; manzanera 'manzanar' (Santander), García Lomas; mazana, cfr. var. (Cabranes), Canellada; manzanera (Bielsa), Badía; mazanal 'manzano' (A. Aller), Rodríguez-Castellano; id. (Lena), Neira; pumar (Colunga), Vigón; manzaneiro y manzanal (bable occid.), Rodríguez-Castellano; pomera 'manzano' y poma 'manzana' (A. Ribagorza), Haensch; maguillo 'manzano silvestre' y maguilla 'fruto', y manzanera 'manzanar' (Rioja), Goicoechea; mazanal y mazana (Cabrales), Fernández-Cañedo; id. (Anguiano), Echaide; manzanero 'manzano' (Villena), Torreblanca; manzano en ALA, 1056; ALC, VII, 1104; ALEA, II, 362; ALEANR, III, 376, ALEICAN, I, 263; ALVA, 1086.

\section{MELOCOTONERO/PIESCO/PAVIA}

(Prunus persica)

Rosáceas

Arbolillo caducifolio con ramitas endebles, hojas lanceoladas con el margen finamente dentado. Flores rosadas y fruto, el melocotón, es globular y rugoso. Hay variedades: fresquillas, duraznos, friscos, pavías, etc. Florece en febrero y se cría en vegas y regadíos. Las flores son laxantes y sus hojas y almendras se han usado como calmante y en perfumería. 
DL: melocotonal, melocotón, melocotonero (B), (BEC); pavial, pavio y melocotonero (MyA). Var. martacón (BEC).

OV: mortocón (La Ribera), Llorente; malacatón (Rioja), Goicoechea; id. (Tierra de Barros. Extr.), Murga; malacatón y malacatonero (Orihuela), Guillén; maracatonero 'melocotonero', malacatón y maracatón 'melocotón' (Villena), Torreblanca; melocotonero, melocontón y dorasnal (Sayago), Borrego; pesegueiro 'árbol que da pesigos', pesguero, piesquero y piescal, pescal y pesical, pésigo, pérsigo, pérsico $\left(3 .^{\mathrm{a}}\right.$ y $4 .^{\mathrm{a}}$ acepciones del Dic. Acad.), y en el resto de la provincia piesgo, piescu, pesco, pesigal y también pesqueiro, 'árbol que produce el pesco' (bable occid.), Acevedo; pescal (Bierzo), García Rey; piescal o piezcal árbol que produce los piescos o piezcos y pérsico o melocotón bravío (Santander), García Lomas; piescu 'melocotón' y pesigo, pescal, pescar, piescal, piescar 'melocotonero' (Cabranes), Canellada; precieco 'melocotón' (Bielsa), Badía; piescal 'una clase de melocotón'; piesco 'fruto del piescal (A. Aller), Rodríguez-Castellano; piescal y su fruto el piscu (Lena), Neira; piescu, pésego y pesco (Colunga), Neira; pisqueiro y piscal una variedad del albaricoquero o melocotonero' (bable occid.), Rodríguez-Castellano, pescal, piesca, piescar 'árbol que da piescos', piescu 'fruto semejante al melocotón y albaricoque con piel recubierta de pelusa' (Cabo Peñas), Díaz; pavial y pavio 'nombres que recibe el árbol que produce los frutos llamados pavias (Maragatería y A.), Alonso Garrote; pavial (Bierzo), García Rey; melocotonero en ALA, 1066; ALC, VII, 1114; ALEA, II, *354; ALEANR, III, 364; ALEICAN, III, 1084; ALES, 213; ALVA, 1096 y pavía en ALEANR, III, *363.

\section{MEMBRILLERO}

(C y don i a oblong a)

Rosáceas

Arbolillo de ramas duras, hojas ovales y enteras, con peciolo corto. Las flores están axiladas y son grandes de color amarillo, blancas o rosas. El fruto, el membrillo, es periforme y tiene cubierta su piel de borra; es oloroso y su carne dura y áspera. Florece en mayo y se cría en setos, cerca de arroyos y tierras de regadío. Se ha utilizado como patrón para injertar perales. Sus frutos se emplean en conserva, confituras y es útil para cortar diarreas.

$\mathrm{DL}$ : membrillero (BEC), (CyV), (B); membrillo (BEC), (CyV); membrillal y membrillar (BEC).

OV: membrillo (La Ribera), Llorente; marmechal (Lena), Neira; marmitsu 'membrillo' (bable occid.), Rodríguez-Castellano; condóñ (A. Ribagorza), Haensch; membrillar 'árbol que da membrillos; no son abundantes, pero en muchas huertas de frutas hay alguno' (Villacidayo), Millán; membrillo en ALA, 465; ALC, III, 500; ALVA, 493. 


\section{MIMBRERA}

(S a lix purpurea)

Salicáceas

Arbusto con ramas flexibles y lustrosas de color púrpura, pardo rojizas. Hojas con corto peciolo, estrechas, lanceoladas y finamente dentadas; el fruto es capsular. Florece en enero y se cría a orillas de cursos de agua en zonas de baja montaña. La corteza es tánica y las hojas y flores tienen propiedades sedantes y astringentes; se ha utilizado para lavar heridas y como antiespasmódico y calmante de la excitación sexual.

$\mathrm{DL}$ mimbre (ML), (CyV), (BEC), (B); bimbre (CyV), (ML), (BEC); brimbia (B), (MyA), (ML), (MR); bimbria (CyV); blima (MR); brimbial (ML); corrizo/-a de paleiro (B); narcal y salguero, balsa y balsero, mimbrera, palera y sarga (BEC). Var. vara francisca (MyA).

OV: salgueira, šalgueira y brimga 'mimbre' (Sanabria), Krüger; bringa y blima (bable occid.), Acevedo; bimbre y brimbe 'cada una de las ramas largas, delgadas y muy flexibles del arbusto llamado sauce o mimbrera'; y vimbral 'mimbral, sitio poblado de mimbreras' (Maragatería y A.), Alonso Garrote; bimbre y bimbral 'mimbre y mimbrera' (Santander), García Lomas; blimal 'arbusto que da blimes'; blima y blimba, blimbal, blimeral 'mimbre' (Cabranes), Canellada; mimbre 'arbusto parecido a la mimbrea' (Bielsa), Badía; brimbia 'mimbre' y brimbial 'mimbera' (Babia y L.), Álvarez; vimbral 'mimbral, sitio poblado de mimbreras', bimbre (La Lomba), Morán; bimbre, brimbia, bime, mimbre 'mimbre' (Cabrera), Casado; bimbre y bimbria 'mimbre', bimbrero 'mimbrera'; también mimbre, fusera 'la empleada para hacer cestos y cañizos', mimbre común y mimbre francisa 'variedad de este arbusto en la región'; corriza 'mimbre retorcida' (Bierzo), García Rey; bimbrera y brimbe 'mimbrera' (Andal.), Alcalá V.; blimba 'mimbre', blimal 'mimbrera' (A. Aller), Rodríguez-Castellano; blimal 'mimbrera' (Lena), Neira; blimar, brimbal, blimbeim y bimbrial 'mimbrera' (Lena), Neira; blimar, brimbal, blimbeiru y bimbrial 'mimbrera'; brimba, bringa y brimbria 'mimbre' (Colunga), Vigón; vima (bable occid.), Rodríguez-Castellano; brimbia y blima 'mimbre' (Sajambre), Fernández González; brimbrera, bimbinera, verduguera 'mimbrera' (A. Ribagorza), Haensch; celgatillo 'mimbrera' (Rioja), Goicoechea; bimi y bimbria 'mimbre'; banieya 'mimbre seco que se emplea para hacer cestas' (Cabrales), Fernández-Cañedo; membreño 'mimbrera' (Rioja), Goicoechea; mimbrera 'planta cuya rama son los mimbres' (Bureba), González-Ollé; blima 'mimbre, se dice del árbol y de las ramas que se utilizan para hacer cestos' (Cabo Peñas), Díaz; brimbi 'mimbre' (Coria), Cummins; brimbal 'mimbrera' (El Rebollar), Iglesias; mimbrera 'mimbrera' y bimbre 'cada uno de los vástagos de la mimbrera, también utílizase vimbrera y vimbré (Cuenca), 
Calero; mimbre en ALA, 1220; ALC, VIII, 1625; ALEANR, III, *397; ALVA, 1249.

\section{MORAL}

(Morus nigra)

Moráceas

Árbol con ramas gruesas y rugosas; hojas acorazonadas y dentadas en los bordes. Flores separadas en gatillos; los frutos se agrupan y forman una mora rojiza oscura de sabor agridulce. Florece en primavera; se cría en plantíos y ribazos como árbol de sombra. La corteza de la raíz es laxante y el jarabe obtenido de sus frutos se ha utilizado contra inflamaciones de garganta y boca.

La morera (Morus a l ba) es parecida y con hojas brillantes y fruto blanco, rosa o púrpura y pedúnculo largo. Se ha cultivado como ornamental y para alimento de gusanos de seda.

$\mathrm{DL}$ : moral y morera (BEC), (MyA), (ML), (B); moral de mora negra y moral de mora roja (BEC).

OV: muera 'fruto del moral' (Bielsa), Badía; mourero y mourera (bable occid.), Rodríguez-Castellano; chordón 'fruto de la morera, mora' (Rioja), Goicoechea; moral 'árbol que da frutos parecidos a las moras silvestres, un poco mayores y de forma alargada. Cuando nacen son de color rojo y luego van volviéndose negras' (Cabo Peñas), Díaz.

\section{MOSTAJO}

( $\mathrm{Sorbus}$ aria)

Rosáceas

Árbol de copa abierta y tronco liso con corteza gris oscura; hojas elípticas y aserradas con corto peciolo y nervación pronunciada, visiblemente blancas por el reverso. Flores blancas, formando pequeños corimbos y fruto ovoide y carnoso de color escarlata. Florece en mayo y se cría en lugares rocosos, bosques secos y matorrales altos.

DL: amusteyo, musteio (CyV); mostajal, mostaja, mostayo y mostajo (MR); bostacho y amustayal (ML). Y el fruto mostaja (MR).

OV: amustayal 'mustaco común. Se llama en otras partes cimaya, mogera, mostaja; el fruto mustaya (La Lomba), Morán; mostaya 'árbol del monte'; mostayera 'cierto arbusto silvestre que da unas bolitas redondas y rojas (A. Aller), Rodríguez-Castellano; mosteya 'arbusto silvestre', en Lena mostayu (Colunga), Vigón; mostayo 'árbol de monte. De él se sacaba la madera para la mayor parte de las piezas del carro' (Sajambre), Fernández González; moišera 'mostajo' (A. Ribagorza), Haensch; mostaju 'mostajo o mostellar' (Pas), Penny; mostajeru 'mostajo' (El Rebollar), Iglesias. 


\section{MUNDILLO}

(Viburnum opulus)

Caprifoliáceas

Arbusto caducifolio de ramas grisáceas, hojas pecioladas y divididas en lóbulos, irregularmente dentadas; flores blancas o rosadas formando vistosas inflorescencias. El fruto es globular, carnoso y de color rojo. Florece en mayo y se cría en setos, bosques húmedos y matorrales. Los frutos se utilizan para hacer licores y su corteza tiene propiedades sedantes y antiespasmódicas.

$\mathrm{DL}$ : copo de nieve y bola de nieve (BEC); mundillo (B).

OV: mundillo 'arbusto', Acad.

\section{NÍSPERO}

(Mespilus germanica)

Rosáceas

Árbol de tronco tortuoso y algo espinoso, con hojas lanceoladas, duras, vellosas y de bordes enteros. Flores grandes y solitarias de color blanco y fruto globoso de color castaño oscuro y acídulo. Florece en el otoño; se cría asilvestrado en sotos y bosques y es resistente al frío. En medicina popular se ha utilizado contra las molestias intestinales y los dolores de boca y garganta.

DL: níspero (BEC); ñisparo (CyV); ñispero (ML).

OV: niseiro 'níspero', niso, níspola 'fruto del niseiro y cadápanos 'nísperos' (bable occid.), Acevedo; ñispero (Cabrera), Casado; abalejal o abadejal 'níspero común'. En Cabuérniga corren las formas abadejo y abadejal; abadejo y abalejo es el fruto del níspero (níspola) o abalejal que cuando está maduro o 'patojo' tiene un sabor dulce y agradable; también niespo 'níspero' (Santander), García Lomas; ñisal 'árbol que da ñisos'; 'prunos más dulces que los corrientes; y nisa 'ciruela pequeña' (Cabranes), Canellada; ñispero 'níspero, árbol y fruto del mismo' (La Lomba), Morán; nispolera, nisporera y níspero (Jaca), Alvar; nísporo 'níspola, fruto del níspero' (Andal.), Alcalá V.; nisperero 'níspero', nispela 'fruto'; carápanu y cagámpanu (Colunga), Vigón; nisperero (Tenerife), Alvar; ñesperu (Cabrales), Fernánez-Cañedo; niespero (Bureba), González-Ollé; niespra 'níspero/-a' (Pas), Penny; nispolero (Villena), Torreblanca; nispero en ALEA, II, *360; ALEANR, III, 372; ALEICAN, I, 255; ALES, 222.

\section{NOGAL}

(Junglans regia)

Juglandáceas

Árbol de copa ancha y corteza gris fisurada; hojas compuestas, puntiagudas y dentadas. Flores blanquecinas formando ramilletes colgantes. El 
fruto es oval y rugoso, cuyo interior está ocupado por la nuez. Se cría en bosques, huertos y riberas. La parte externa y carnosa del fruto, las hojas y la corteza son tintóreas; y las hojas y los frutos son astringentes. El aceite de nueces es vermífugo y hace descender la cantidad de azúcar en la sangre y en la orina.

DL: nogal (BEC), (CyV), (ML), (B); anogal (CyV), (BEC), (MyA); noguera (BEC); nozal, ñogal y cusial (ML); nozal (MR); conchal (CyV).

OV: noceiro 'nogal'. En el centro de Ast. nozal alterna con noceira (bable occid.), Acevedo; conchal 'nogal'; concho y conjo 'nuez' (Bierzo), García Rey; cucal 'nogal', cuca/-o 'nuez' y cuculina 'nuez pequeña o raquítica'; cucalera 'nogalera' (Santander), García Lomas; ñozal 'nogal', ñuez 'nuez' y ñozalera 'conjunto de ñozales' (Cabranes), Canellada; la nogal 'el nogal' (Cabrera), Casado; anoales y en singular es la noal y la nogal (Maragatería y A.), Alonso Garrote; coquero 'nogal'; coca 'nuez' (Aragüés), González Guzmán; coquera 'nogal' (Jaca), Alvar; nozal (A. Aller), Rodríguez-Castellano; nozal, 'nogal' y nozaliru, nozalera 'nocedal' (Lena), Neira; nozal y noceu 'nogal' y nozaleda 'nogueral' (Colunga), Vigón; conchal, zozal, nogal, nuceiro, nozal y noceo 'nogal', el fruto: concho, nuaz, nuoz; y nuzedal, nogaleiro, nocedera 'nogueral' (bable occid.), Rodríguez-Castellano; cunsial (Laciana), Álvarez Guzmán; nuecero (Tenerife), Alvar; nozal (Sajambre), Fernández González; id. (La Lomba), Morán; id. (Cabo Peñas), Díaz; ñozal (Cabrales), Fernández-Cañedo; id. (Cabo Peñas), Díaz; ñogal 'nogal' y ñuez 'nuez' (Valle Gordo), Rubio Álvarez; cunchal 'nogal' y conchu 'nuez' (Sisterna), J. A. Fernández; noguero 'nogal', nou 'nuez' y nogueral y nugueral 'nogueral' (A. Ribagorza), Haenchs; noceo y noguero 'nogal', nocedo y nogalera 'nogueral' (Rioja), Goicoechea; nugal, nuezal, nuzal, cucal 'nogal', cuca 'nuez' (Pas), Penny; noguera 'nogal' (Villena), Torreblanca; nogal en ALA, 972; ALC, VII, 1020; ALEA, II, *351; ALEANR, III, 358; ALEICAN, I, 260; ALVA, 1002 .

\section{OLIVO (Silvestre)}

(O lea europa ea)

Oleáceas

Árbol retorcido y nudoso con ramas finas y derechas; hojas ovallanceoladas con bordes enteros; flores blancas formando racimitos en las axilas de las hojas. El fruto, la oliva o aceituna, varía de tamaño, forma y color. Florece en mayo y se cría silvestre en tierras bajas, matorrales y valdíos; el aceite virgen se destina a usos medicinales y el aceite común se saca después de la primera prensadura. Las hojas se consideran febrífugas y se utilizan para bajar la tensión; con el aceite se preparan ungüentos. 
$\mathrm{DL}$ : olivo (BEC), (B), (CyV); oliva, olivo bravo, olivo silvestre y olivo campestre (BEC).

OV: oliveira (bable occid.), Acevedo; zambuche 'olivo silvestre' (La Ribera), Llorente; olivo macho 'acebuche' (Tenerife), Alvar; olivera y olivé 'olivo'; oliva 'oliva' (A. Ribagorza), Haensch; asembuche 'acebuche, olivo silvestre de monte' (Orihuela), Guillén; azauche (Extr. Valencia de Alcántara), Murga; acebuche 'olivo silvestre', Acad.; id. en ALEA, III, *311; ALEANR, III, *299.

\section{OLMO}

(Ulmus minor)

Ulmáceas

Árbol con corteza rugosa y fisurada, con hojas irregularmente ovales, puntiagudas con los márgenes dentados. Las flores rojas o amarillentas crecen en racimos pequeños. Los frutos son alados y transparentes. Florece en abril y se cría en setos, laderas y caminos. La corteza con abundante tanino, se utilizaba para pomadas contra enfermedades de la piel y como remedio eficaz contra los catarros bronquiales.

$\mathrm{DL}$ i negrillo (BEC), (B), (CyV), (MyA), (ML), (MR); llameira y negrillal (CyV); olmo (BEC); ulmeiro (B), (CyV); llamera (MR); tsamera (B) y (ML).

OV: llamera y tsamera 'olmo' y páxara 'fruto alado del olmo' (Colunga), Vigón; orm 'olmo' (A. Ribagorza), Haensch; umeru 'olmo' (Cabrales), Fernández-Cañedo; negrillo 'olmo o una variante de éste' (Villacidayo), Millán; id. (Sayago), Borrego; olmo 'con hoja casi en forma de corazón' y olma más alto, con hoja alargada, amarillenta y efímera (La Roda), Chacón; olmo en ALEA, II, *377; ALEANR, III, 399.

\section{ORÉGANO}

(Origan um vulgare)

Labiadas

Arbustillo poco elevado con hojas pequeñas, redondeadas en la base y lanosas por el envés. Flores de color rosado o blanco formando espigas terminales; fruto seco y globoso. Crece en verano y se cría en laderas y tierras bajas. Utilizada por sus propiedades tónicas y estimulantes, es antiséptico y amortigua los dolores provocados por los nervios.

$\mathrm{DL}$ : orégano (ML), (B), (CyV), (MR) y (BEC); oriégano (BEC), (MR), (ML); urégano o uriégano y var. oreganin y orégano nano (MR).

OV: orégano 'orégano' y en la parte central de Ast. oriéganu (bable occid.), Acevedo; id. (Cabranes), Canellada; id. (Colunga), Vigón; id. (Cabrales), Fernández-Cañedo; uriéganu (La Ribera), Llorente; oriégano (La 
Lomba), Morán; id. (A. Aller), Rodríguez-Castellano, id. (Maragatería y A.), Alonso Garrote; id. (bable occid.), Rodríguez-Castellano; id. (Sajambre), Fernández González, id. (Villacidayo), Millán; uriégano, ouriégano, auriégano (bable occid.), Rodríguez-Castellano; ouriéganu (Sisterna), J. A. Fernández.

\section{PARRA SILVESTRE}

(Vit is labrusca)

Vitáceas

Planta trepadora leñosa con robusta raíz y tallos sarmentosos, posee unos zarcillos ramificados opuestos a las hojas. Flores amarillo verdosas formando racimos colgantes; el fruto es ácido, negro azulado. Antecesora de las cultivadas, aparece frecuentemente asilvestrada. Se cría en todo tipo de terreno desprovisto de cal.

DL: parra brava, vid silvestre, viña de injerto, viña (BEC); parra (ML), (MyA), (B); cepa y vid (B), (CyV); vid brava (CyV).

OV: piñal 'vid o parra silvestre' y piña 'racimo silvestre' (A. Aller), Rodríguez-Castellano; Acad. vid salvaje o silvestre. La no cultivada que produce las hojas más ásperas y las uvas más pequeñas y de sabor agrio.

\section{PERAL}

(P y rus communis)

Rosáceas

Árbol de corteza escamosa, inerme o espinoso, según las distintas variedades. Hojas elípticas, pecioladas y lampiñas con margen casi entero; flores blancas o rosadas dispuestas en corimbos. El fruto, la pera, tiene forma muy variable. Florece en abril y se cría en setos, regadíos y huertas. La asilvestrada es más dura y compacta, de color pardo rosado o rojizo.

DL: peral (todas); peral montisco (MR); perullal (B); peral (la), (CyV) y fruto: perucha o pera montisca (MR). Var. gabusia (ML).

OV: pereiro y pereira, también peruyeiro 'árbol que da peruyos o peras pequeñas' (bable occid.), Acevedo; galapero 'peral silvestre' (La Ribera), Llorente; perullal 'árbol que produce el perullo 'pera pequeña y temprana' (Bierzo), García Rey; la peral (Cabrera), Casado; peruyo 'especie de pera pequeña, muy sabrosa, llamada en castellano pera cermeña o cermeño', otra variedad es la coruja 'pera inverniza, muy estimada para hacer compotas y confituras, pero dura e insípida cuando se recolecta' (Maragatería y A.), Alonso Garrote; perojal, perujal, pirujal 'árbol que produce perojos, pirujos o perujos (Santander), García Lomas; peruyal 'árbol que da peruyes', peruya 'pera pequeña de mala calidad' (Cabrales), 
Canellada; piruyal 'peral silvestre', peruya 'pera pequeña silvestre' (A. Aller), Rodríguez-Castellano; id. (Lena), Neira, y piruya 'fruto silvestre pequeño y rojizo en forma de pera'; peral 'peral', el peral silvestre peruchal y perucho, piruxetso, peruchal 'fruto pequeño y de mal sabor'; y piruyeiro y su fruto piruyo (bable occid.), Rodríguez-Castellano; piruchal 'pera silvestre' (Sisterna), J. A. Fernánez; peruyal 'peral' (Cabo Peñas), Díaz; perera (A. Ribagorza), Haensch; pero (Rioja), Goicoechea; perojal, pirujal, pereluzu de surbitu, peruétanu, el fruto piruju y pl. peruxus, surbitus (Pas), Penny; perero 'árbol que produce el pero', peretero 'peral que produce la pereta' (Orihuela), Guillén; galaperu 'peral silvestre' (Coria), Cummins; fragatúa 'peral bravío y de espinas gruesas, dañino por ser fruto malo' (Extremadura), Murga; perucos 'peras tempranas de pequeño tamaño, dulces y sabrosas (Villacidayo), Millán; perucbu 'pera bravía' (El Rebollar), Iglesias; peral en ALA, 1027; ALC, VII, 1075; ALEANR, III, *373; ALVA, 1056.

\section{PINO PIÑONERO}

(Pinus pinea)

Pináceas

Árbol con copa redondeada y corteza parda grisácea que se desprende fácilmente dejando ver areolas anaranjado-rojizas. Hojas finas, rígidas y punzantes. Piñas agrupadas o solitarias con piñones con un ala membranosa que se desprende con facilidad. Florece en abril y se cría en terrenos sueltos, frescos y zonas arenosas. La corteza, rica en taninos, se ha usado para curtir pieles y los piñones se han considerado balsámicos y apropiados contra la tos y enfermedades del pecho.

DL: pino de piñones, pino real, pino piñonero (BEC); pino (todos).

\section{PINO RESINERO}

(Pinus pinaster)

Pináceas

Árbol piramidal de joven y los de edad con copa redondeada, corteza áspera y muy fisurada. Hojas largas, retorcidas y punzantes. Piñas cónicas y dentadas de color rojizo, portadora de piñones largamente alados. Florece en primavera y se cría en colinas, suelos arenosos y desprovistos de cal. Su corteza es astringente y sus brotes tiernos se han utilizado para combatir catarros y enfermedades bronquiales.

$\mathrm{DL}$ : pino resinero, pino de resina $(\mathrm{B}),(\mathrm{CyV})$; pino bermejo $(\mathrm{MR})$; pino negral (CyV).

OV: pino en ALA, 1036; ALC, VII, 1084; ALVA, 1065. 


\section{PINO SILVESTRE}

(Pinus sylvestris)

Pináceas

Árbol de tronco recto de corteza rojiza y escamosa en la parte superior y los más viejos con corteza fisurada. Hojas estrechas y puntiagudas. Sus piñas son cónicas y pedunculares. Florece en primavera y madura sus piñas en el otoño siguiente; se cría en tierras bajas. El aceite de pino destilado se usa contra los catarros bronquiales, el reumatismo y las infecciones de la sangre.

$\mathrm{DL}$ : pino y pino silvestre (BEC).

OV: escupineiro 'pino' (Bierzo), García Rey; piñal 'pino y pinar' (Santander), García Lomas; pino y pi, pl. pins 'pino' (A. Ribagorza), Haensch; pino id. cast. (Pas), Penny.

\section{PIORNO}

(Genista florida)

Leguminosas

Planta perennifolia con tallos leñosos y ramas amarillentas, flexibles. Hojas alargadas cortamente pecioladas de envés blanco sedoso; flores amarillas olorosas en racimos y fruto en vainas oblongas y aplastadas con una o dos semillas. Florece en marzo y se cría en piornales, claros de monte alto, siempre que sean lugares frescos y sin cal.

DL: piorno (CyV), (MR), (BEC), (B), (MyA); peorno (ML), (B); escoba (ML); escoba blanca (MyA); piorno blanco y piorno amarillo (CyV); piormu albar y piornu morisco (ML); zusca (MR).

OV: piormu 'especie de escoba' (Sanabria), Krüger; bolaga 'piorno fino sin púas' (La Ribera), Llorente; piornu 'planta perteneciente al género genista. Lo hay de dos clases: albar, gris claro y moriscu, verde oscuro' (Babia y L.), Álvarez; peorno 'piorno' (Andal.), Alcalá V.; piurno 'una clase de retama de tamaño grande' (A. Aller), Rodríguez-Castellano; piurnu (Lena), Neira; piorno 'una clase de retama, de mayor tamaño que la corriente y más leñosa. Crece generalmente en terreno bravío' (bable occid.), Rodríguez-Castellano; peorno y piorno 'retama grande de madera muy dura' (Sajambre), Fernández González; zusca 'retama de piorno, escoba' (Tejerina), Villarroel; vainilla 'fruto del piorno' (Valle Gordo), Rubio. Acad. cayomba.

\section{QUEJIGO}

(Quercus faginea)

Fagáceas

Árbol de tronco derecho, algo tortuoso y de corteza grisácea agrietada y a veces reducida al porte arbustivo por la degradación de los suelos. Hojas 
pecioladas coriáceas, con dientes poco profundos y ocasionalmente punzantes; flores muy pequeñas dispuestas sobre amentos colgantes. El fruto, la bellota, nace de un pedúnculo muy corto con cúpula de escamas aovadas. Florece en abril y se cría en valles, páramos y montañas bajas. Se asocia a encinas, alcornoques, árboles formando híbridos que dificultan la identificación.

$\mathrm{DL}$ : caxigo 'roble joven' (MR); quejigo (BEC) y carcoxa o llata (ML).

OV: caxigo 'retoño del roble' y caxigueiro 'roble tierno' (bable occid.), Acevedo; cajiga o quejigo 'roble joven'; albar 'cajiga o quejigo de grandes dimensiones que no se ha podado nunca'; cajigal y cajiguera 'quejigal, terreno poblado de quejigos' (Santander), García Lomas; cajigal 'quejigal' (Jaca), Alvar; caixico 'roble' (Bielsa), Badía; cacbico y cajico 'roble' (Aragüés), González Guzmán; quišigo (A. Ribagorza), Haensch; cajigá, robre 'roble', no enteramente desarrollado cajigu, joven macharu, achaparrado matoju, agrupación de robles achaparrados matujal y cajigalu, el robledal cajigal (Pas), Penny; quejigo (Cuenca), Calero; quejigo en ALEANR, III, 393; ALES, 234.

\section{QUIRUELA}

(Erica umbellata)

Ericáceas

Arbustillo con ramas leñosas y algo tortuosas; hojas lineares, lampiñas y con el margen revuelto. Flores rosadas formando inflorescencias terminales. Florece en primavera y se cría entre brezales.

$\mathrm{DL}$ : coriega y quiruga (BEC); coriega, quiruga y quiruega (CyV); quiruela y quiruega (MyA).

OV: quiruegas 'las urces de clase inferior, caracterizadas por tener las ramas cortas y abundar en ellas los palos gruesos con escasez de hojas (Maragatería y A.), Alonso Garrote; mogariza, 'planta ericácea de hoja obtusa trígona ternada y flor en umbelas rosadas', quiruela, mogariza, quirola (Sierra Morena), Alcalá V.; queiriña 'planta de la familia del brezo; es baja y sus ramas son leñosas. Abunda mucho en los montes de Asturias'; también: queiruela, greñas, gorbiz, rebilera, gueirueta, rebela, trousa, gairueña y ganza mourial. Acad. queribuela.

\section{REBOLLO/ROBLE MELOJO}

(Quercus pyrenaica)

Fagáceas

Árbol con tronco grueso y corteza cenicienta; hojas caedizas de color verde oscuro y lampiñas por el haz, pálidas por el envés con varios lóbulos estrechos y profundos. El fruto, la bellota, aparece en grupitos sentados y con un corto pedúnculo; la cúpula es escamosa. Florece en 
primavera y se cría en bosques de montaña. Su corteza se emplea para curtir y su leña es de excelente calidad.

DL: rebollo $(\mathrm{ML}),(\mathrm{MR})$; rebolla $(\mathrm{MyA})$; rebotsu $(\mathrm{ML})$; rebolleta y talaya (BEC).

OV: rebolla 'roble pequeño' (Maragatería y A.), Alonso Garrote; rebollar 'lugar poblado de rebollos; son quejigos que echan la hoja muy temprana y que tiene la beta acebollada' (Santander), García Lomas; rebollada (Cabranes), Canellada; rebollo 'roble pequeño' (Valle Gordo), Rubio; rebutsu y reutsu 'roble pequeño' (A. Aller), Rodríguez-Castellano; rebochu 'rebollo' (Lena), Neira; rebotsa 'roble muy joven de tallo delgado' (bable occid.), Rodríguez-Castellano; rebollo 'roble crecido' (Sajambre), Fernández González; rebolleta 'roble de unos dos o tres metros de altura, ya desmochado, pero relativamente joven; y talaya 'roble joven, rebolleta' (Villacidayo), Millán.

\section{RETAMA}

(Ret a m a sphaerocarpa)

\section{Leguminosas}

Arbusto provisto de largas y flexibles ramas de color verde ceniciento y estriadas longitudinalmente. Hojas limear-lanceoladas, escasas y de poca permanencia en la planta; flores amarillas en racimos laterales y fruto de vaina globosa, de color marrón claro y con una sola semilla. Crece en matorrales y terrenos degradados. Se ha utilizado contra afecciones del aparato respiratorio y fiebres eruptivas.

$\mathrm{DL}$ : retama y retrama, jagata, jalgata (BEC); turra y yiesta (CyV); escoba, ratama amarilla (MR); var. morisca 'hojas más escasas que la otra' y el fruto es el zapatín (MR).

OV: yiesta 'retama y sus flores ĉuridas (Cabrera), Casado; escobones 'variedad de retama o hiniesta, más alta que ésta, de ramas vellosas y flores en corimbos', almayón 'retama macho' (Andal.), Alcalá V.; retrama y xiniestas 'retama' (A. Aller); sexta 'retama', xinestra y escoba 'retama genista' (bable occid.), Rodríguez-Castellano; escoba 'retama; la retama tiene la flor más pequeña que el piorno' (Sajambre), Fernández González; iscoba 'retama, hiniesta' (Sisterna), J. A. Fernández; retama en ALEA, II, *307; ALEANR, III, 293.

\section{RETAMA DE OLOR}

(Spartium junceum)

Leguminosas

Arbusto junciforme de ramas largas y lisas, y hojas oblongolanceoladas. Flores grandes y olorosas en racimos terminales de color 
amarillo vivo. La legumbre es larga, con los bordes casi paralelos y aplastada. Florece en mayo y se cría en setos, terraplenes, márgenes de caminos. Sus tallos y ramas son tintóreas y se han empleado en cestería; las semillas para piensos y en medicina, aunque es tóxica debido a un alcaloide, como aparitivas y laxantes.

$\mathrm{DL}$ : retama de olor, retrama y escoba (BEC).

OV: siñesta (Genista ju ncea) (bable occid.), Rodríguez-Castellano.

\section{ROBLE}

(Quercus petrea)

Fagáceas

Árbol con tronco grueso y grandes ramas extendidas, de corteza grisácea muy resquebrajada en ejemplares añosos. Semejante al (Q u e r c u s robur) con hojas lobuladas con peciolo poco desarrollado y cuneadas en la base. Flores de color verde amarillento en amentos y fruto, la bellota, largamente ovoide, pedunculada y amarga. Florece en abril y se cría en laderas, suelos sueltos y profundos formando frecuentemente híbridos con hayas, pinos y otros robles. Antigualmente se elaboraba pan con la bellota; la corteza sirve para curtir pieles y las agallas para hacer tinta.

$\mathrm{DL}$ : roble (todos); roble matiego (BEC); roble matizo, alcorque y carbayo (MR).

OV: rebutsu cocoxo 'una clase de roble de poca altura' y también casomera curcutsu; la bellota del roble es tsandre (A. Aller), RodríguezCastellano; llata 'roble joven y alto' (La Lomba), Morán; veceña 'roble pequeño y raquítico' (Rioja), Goicoechea; robri 'roble' (Cabrales), Fernández-Cañedo; robre (Anguiano), Echaide y Soralegui; barda 'roble aún pequeño' (Béjar), Marcos; robri (Las Hurdes), Murga; roble en ALA, 1110; ALC, 1158; ALEANR, III, 392; ALVA, 1140.

La agalla del roble, boyaca se denomina: cascarela 'agalla del roble distinta de la beilara y de la llanda, en Tineo pan de cuquiello, en Franco mazá de carbayo (bable occid.), Acevedo; gállara y títere 'excrecencia del roble' (Santander), García Lomas; buyaca 'agalla esférica del roble, mayor que el jogo, de color pardo café, con algunas excrecencias o picos de forma cónica y escasa altura repartidos por la superficie. Fuyaca es empleado en Maragatería, como buyaca se dice en Astorga. El jogo es la agalla o excrecencia del roble, esférica, dura y más pequeña que la buyaca' (Maragatería y A.), Alonso Garrote; fuyaco 'fruto del roble' (Bierzo), García Rey; fraile 'agalla del roble' (Valle Gordo), Rubio; gallarota/-o 'esferilla muy ligera que crían los robles y que debe servir de 
nido a la larva de alguna mosca'; algallara 'agalla', cucarra 'agalla en forma de bolita, que se forma en la rama de las encinas y robles por la picadura de algunos insectos', y cucaraballa 'fruto del roble' (Rioja), Goicoechea; cascabuyo o buyaca (Aliste), Baz; pirulita, bailarina, gallarita (Pas), Penny; algallara 'excrecencia parasitaria del roble', también abogallas, bogallas, agallarras, algallarines, gallarutos y toras (Béjar), Marcos; chivo 'agalla del roble' (Extrem.), Murga; bogaya, bogaja, bobaja y buyaca (Sayago), Borrego.

\section{ROBLE ALBAR}

(Quercus robur)

Fagáceas

Árbol de tronco corto y robusto, copa amplia y corteza muy fisurada; hojas pecioladas, acorazonadas con el borde de lóbulos redondos. Flores colgantes verde-amarillentas las masculinas y pardo-rojizas las femeninas; el fruto, la bellota, sin rabillo. Florece en abril y se cría en suelos compactos, profundos y algo húmedos. La madera es dura, pesada y muy resistente a la putrefacción. Los frutos pueden comerse y se usan también para pienso; la corteza y las agallas de las hojas son tánicas.

DL: roble albar (BEC); carvayu, carvallo y roble marfueyo (MyA); rebollo albar (MR).

OV: carbayo 'roble'; en el centro de la provincia carbayu; carbayedo 'robledal'; en cast. carvallar y carvalledo; úsase en la mayor parte de Ast. carvalleira 'soto de robles y áun de robles, castaños y abedules mezclados; carvallo 'roble en pie, pues a la madera de este árbol, aserrado o en grumo, se le llama roble; en bable carbayu y carvayo; en Maragatería Alta carvayu (Maragatería y A.), Alonso Garrote; carbayu 'roble', carbayeda (V. carbayera, roblera, rebollera) 'sitio de muchos carvayos' (Cabranes), Canellada; roble albar (Lena), Neira; carbayu (Colunga), Vigón; rebotso y rebosu 'roble' (Q u e rcus robur). Hay diversos tipos de roble: rebotso turcu y rebotso curcu 'roble bajo y de hojas estrechas', rebotso albar 'roble alto y de muy buena clase', rebotso cuartial 'alto' y camayo 'roble que no pasa de arbusto' y lo mismo el sapiego, y el potsisco 'roble bajo y de poco desarrollo' o potsiscu curcu, también cabayo y carbacho. El robledal se denomina carbayeira, carbayera, carbayeo, carbacheu, rebotsal, rebusar, carbayal y rebutseo. Su bellota es la abechota, tsandre y sandre (bable occid.), Rodríguez-Castellano; carbayo 'roble de mala madera, pero muy buena leña'; albar 'rebollo albar', otra clase de roble (Sajambre), Fernández González; carbachal 'roble' y carbachu alvar 'roble de hoja ancha' (Sisterna), J. A. Fernández; carbayo 'roble' (Aliste), Baz. 


\section{ROMERO}

(Rosmarinus officinalis)

Labiadas

Arbusto perennifolio y aromático, verde todo el año; los tallos añosos se presentan con la corteza fisurada. Hojas lineales, gruesas, coriáceas, por un lado verdes y por el otro blancas. Flores de color azul pálido formando ramilletes. Se cría en lugares secos, matorrales, colinas. De él se obtiene la esencia de romero, es estimulante, antiespasmódico y combate los dolores articulares.

DL: romero (todos).

OV: romeiro (bable occid.), Acevedo; romiru (Lena), Neira; rumeiro (bable occid.), Rodríguez-Castellano; romé (A. Ribagorza), Haensch; romero en ALA, 1100; ALC, VIII, 1148; ALEANR, III, *291; ALVA, 1130.

\section{RUSCO}

(Ruscus aculeatus)

Liliáceas

Arbusto perennifolio con tallos gruesos, flexibles y estriados; hojas reducidas a menudas brácteas membranosas de figura lanceolada y espinosamente puntiagudas. Las flores son verdosas o blanquecinas y el fruto es una baya globular de color rojo. Se cría en tierras bajas y matorrales. Sus brotes tiernos se han utilizado como diuréticos y aparitivos; es antihemorroidea y antivaricosa.

DL: carrasco (CyV); rusco y sardonera (BEC).

OV: escobizo 'arbusto llamado brusco para hacer escobas', escobaliza lugar de muchas escobizas o escobas', y escobino 'escoba o matorral espeso como el del brusco y otros semejantes' (Santander), García Lomas; brusco 'arbusto muy ramoso del que se hacen escobones' (Andal.), V. Alcalá.

\section{SABINA (RASTRERA)}

( $J$ uniperus sabina)

Cuprasáceas

Arbusto con tronco grueso y corteza de color pardo rojizo y ramas extendidas, rastreras y de poca altura. Hoja perenne en forma de escamas; fruto globoso, pequeño, negro azulado. Florece en abril y se cría en prados, bosques y roquedos montañosos. Se ha empleado en medicina popular, aunque es venenoso, para favorecer la menstruación y detener hemorragias uterinas.

$\mathrm{DL}$ : sabina rastrera (ML). 
OV: sabin 'sabina, planta' (Andal.), Alcalá V.; sabino 'sabina, arbusto conífero' (Rioja), Goicoechea; sabina rastrera (Cuenca), Calero. (Juniperus communis sob. nana o alpina).

\section{SALGUERO/-A}

(S a lix atrocinerea)

Salicácea

Árbol con ramas alargadas y flexibles; hojas lanceoladas, enteras o con dientes gruesos y poco marcados. Flores en amentos verdosos; la semilla es capsular. Florece en enero y se cría en terrenos frescos, a orillas de corrientes de agua. Es una planta que se hibrida con otros sauces dificultando su reconocimiento. Una variedad endémica en León es la (Salix cantabrica).

$\mathrm{DL}$ saguero/-a (todos); sauce (ML), (BEC); salgueiro/-a (B), (CyV); salgueriza (MyA); salgueiru (ML); salgueru, salguiru y balsero (MR); balsero, palera y var. ramal (BEC).

OV: salgueiro 'arbolillo que la Acad. llama orgaza. Sus varitas son flexibles, y se emplean en algunos tejidos y para hacer los niños sus pesugos y silbatos', us. salguero y salguera significando 'sauce' (bable occid.), Acevedo; salgueira 'salguera' (Bierzo), García Rey; salgueira 'salguera' y salgueral 'salgueral' (Cabrera), Casado; sagallino 'sargatillo o especie de sauce cuyas ramas se emplean en cestería y algunos aperos' (Santander), García Lomas; salgar, salgueru 'arbusto que crece en las sebes, tiene unas varas largas y finas; se descorteza con mucha facilidad y se emplea para hacer cestos', la salguera como el salgueru, pero con más frondosidad (Cabranes), Canellada; salieto 'sarga, variedad de la mimbrera; sus ramas se usan para hacer cestos' (Bielsa), Badía; salgueiru 'salguero' (Babia y L.), Álvarez Guzmán; salguero 'una especie de sauce; crece al lado de los ríos y arroyos', salguera 'sitio de muchos salgueros' (A. Aller); Rodríguez-Castellano; salguiru (Lena), Neira; salgar 'sauce blanco'; en Villaviciosa salgueru y salgueiru región occid. (Colunga), Vigón; salgueiro 'cierta clase de sauce' (S alix fragilis). Otra clase más pequeña de salguera; salgueiral 'conjunto de salgueros' (bable occid.), Rodríguez-Castellano; salguero 'árbol', salguero, salgeru, salguiru son formas ast.-leonesas (Sajambre), Fernández González; salgueiru 'sauce' (Sisterna), J. A. Fernández; salciña 'especie de mimbrera', existen las variedades blanca y negra, y son comunes en las orillas del río Oja y Glera (Rioja), Goicoechea; salguiru 'arbusto que crece en las sebes. Sus varas se emplean en la fabricación de cestos' (Cabo Peñas), Díaz. 


\section{SALVIA}

(S a lvia officinalis)

Labiadas

Arbustillo aromático, de tallos herbáceos en el ápice, leñosos cerca de la base y vellosos; hojas lanceoladas, correosas y de borde ondulado. Flores azules, a veces violáceas y fruto seco. Se cría en suelos secos y climas soleados. Es tónica y febrífuga; aminora el azúcar en la sangre y normaliza las funciones menstruales.

DL: salvia (BEC).

OV: salvia 'arbusto de hoja blanca que produce bayas parecidas a la jara', sus hojas tostadas las emplean algunos ganaderos y cazadores para fumar (Andal.), Alcalá V.; salvia 'salvia' (A. Ribagorza), Haensch; id. en ALEANR, III, *292.

\section{SAUCE BLANCO}

(S a 1 ix a $1 \mathrm{~b}$ a)

Salicáceas

Árbol de tronco robusto, de aspecto plateado, ramas ascendentes y flexibles; hojas lanceoladas y vellosas en las dos caras con bordes finamente dentados y con amentos cilíndricos y verdosos. Florece en primavera y se cría en tierras bajas y frescas. Sus ramas se emplean en cestería y se considera antiafrodisíaco al reducir la actividad sexual, sedante y febrífugo; lo emplean también contra el reumatismo y artritismo.

DL: palera (ML), (MyA), (BEC), (CyV); palero (ML), (B); paleiro $(\mathrm{CyV})$; támara y sauce blanco $(\mathrm{BEC})$; salguera blanca $(\mathrm{B}) ;$ sauce $(\mathrm{B})$, (MyA), (ML).

OV: paleiro 'sauce' (Cabrera), Casado; palera 'sauce, salguero, árbol propio de terrenos húmedos o pantanosos' (Maragatería y A.), Alonso Garrote; salcero, salcera y salzamorra (Jaca), Alvar; palero 'sauce blanco' (S a lix a lba) (La Lomba), Morán; salcero y salce (Aragüés), González Guzmán; palera 'especie de sauce, de hojas más verdes y alargadas y de mayor corpulencia', taza 'mimbre de sauce con que se hacen los cestos' (Valle Gordo), Rubio; salse y salze (A. Ribagorza), Haensch; salguera 'sauce' (Cabrales), Fernández-Cañedo; salce (Bureba), González Ollé; palera 'especie de sauce vulgar y basto que en otras partes llaman salguera' (Villacidayo), Millán; salce 'sauce'; salcinal y sauzal 'campo de sauces' (Pas), Penny; azaoz 'sauce' (El Rebollar), Iglesias; saz (Cuenca), Calero; sauce en ALEA, II, 376; ALEANR, III, 397; ALES, 239. 


\section{SAUCE LLORÓN}

(S a lix babylonica)

Salicáceas

Arbolillo de corteza parduzca, ramas finas, largas y flexibles que cuelgan hasta tocar el suelo; hojas lampiñas, alargadas y estrechas con el borde finamente aserrado; flores formando amentos de color verde amarillento y semillas capsulares. Florece en marzo y se cría al borde de estanques y riberas.

$\mathrm{DL}$ : llorón (B), (BEC); mimbre llorón (ML); sauce llorón (BEC), (MyA), (B); sauce, árbol del desmayo, árbol de la bumildad, mimbral (BEC).

OV: llorón 'sauce llorón' (Andal.), Alcalá V.; salce gatillo y salce desmayo (Bureba), González Ollé; salcinu 'sauce pequeño o sauce llorón' (Pas), Penny; desmayo (Cuenca), Calero; sauce llorón en ALEA, II, *376; ALEANR, III, *398.

\section{SAÚCO}

( $\mathrm{S}$ a mbucus nig r a)

Caprifoliáceas

Arbusto de corteza rugosa de color gris pálido y ramas con médula muy desarrollada; hojas compuestas, aovadas y lanceoladas con bordes aserrados. Las flores, amarillas o color crema, despiden un suave aroma, el fruto es una baya jugosa y negra. Florece a partir de abril y se cría en sotos y descampados próximos a arroyuelos. Flores y frutos se han empleado como sudoríficos, para combatir inflamaciones de encías y quitar manchas en el rostro.

DL: sabuco (ML), (B), (BEC), (MyA), (CyA); sabugo (ML), (B), (CyV), (MyA); sabuguero, sabuquero y sabuqueiro (B), (MyA); saúco ( $\mathrm{BEC}),(\mathrm{B})$, (CyV), (MyA); sabugueiro (B), (CyV); saúcal (MyA), (BEC); sabucal y yezgo (BEC); sabugueiru (ML); saügo y siaúco (MR).

OV: sabugeiru 'saúco' (Sanabria), Krüger; binteiro (bable occid.), Acevedo; sacapute, sagú, saugu o samugo y sangú 'saúco', saugal o saucal 'lugar poblado con saúcos' (Santander), García Lomas; benitu 'saúco' (Cabranes), Canellada; sabuco (Maragatería y A.), Alonso Garrote; sabugueiru y sabugo (Babia y L.), Álvarez; sabugueiro 'arbusto o arbolillo muy común en todo el Bierzo'; otras denominaciones sabuguero, sabuquero, sabuqueiro (Bierzo), García Rey; sabugueiro (Valle Gordo), Rubio; samuaquer 'arbusto cuya flor se llama samuco, flor del saúco' (Bielsa), Badía; xabú (A. Aller), Rodríguez-Castellano; sabucu y sabuyu (Colunga), Vigón; sabugo, sabú, binteiro, beneito (bable occid.) RodríguezCastellano; saúgo (Tenerife), Alvar; saugo y siaugo (Sajambre), Fernández González; xirical y bineitu (Sisterna), J. A. Fernández; sauquero y sauqué 
(A. Ribagorza), Haensch; saúgo (Cabrales), Fernández-Cañedo; šabugu y šabú (El Cabo Peñas), Díaz; cañolero (Aliste), Baz; sabugo, pl. sabugos (Pas), Penny; cañilero, sabuguero, canillero y saúco (El Rebollar), Iglesias; saúco en ALA, 1125; ALC, VIII, 1174; ALEA, II, 374; ALEANR, III, 395; ALES, 237; ALVA, 1157.

\section{SERBAL SILVESTRE}

(Sorbus a cuparia)

Rosáceas

Árbol de corteza lisa y grisácea; hojas compuestas en disposición alterna, con foliolos oblongos y bordes aserrados; flores blancas y muy olorosas agrupadas en corimbos terminales; el fruto, la serba, es globular de color escarlata. Florece en mayo y se cría en laderas frescas y zonas montañosas mezclado con otras especies. Con la fermentación de sus frutos se obtienen licores. Sus mermeladas y jarabes son antiescorbúticos y se han empleado contra diarreas y hemorroides.

DL: cornabute (CyV); capudro (ML), (MyA); capudre (B); capudo (ML); serbeira brava y escornabois (B); argumón, argomeno, argumeno $\mathrm{y}$ argamón (MR); argumenu (ML); serbal (BEC).

OV: sorbital 'peral silvestre o serbal común'; sorbitos 'fruta del peral silvestre sorbital o serbal. Serbas (Vid. ceremeño' (Santander), García Lomas; alcafrisnu (pl. alcafresnos), Alcafresna, serbal; argomenu 'serbal del cazador' (Colunga), Vigón; bezurc y bezurt 'serbal' (A. Ribagorza), Haensch; zurbal 'serbal' y zurba 'serba, fruto del serbal', poma 'fruto del serbal llamado también poma de monte y pomar árbol que da un fruto llamado poma, serbal (S o rbus a u cuparia) (Rioja), Goicoechea; jerbal 'serbal, árbol frutal', serba 'fruto del serbal; es parecido al níspero' (Bureba), González Ollé; capudo 'serbal silvestre' (Tejerina), Villarroel; caputre y capudro 'árbol que produce un fruto arracimado, no comestible, de color rojo' (bable occid.), Rodríguez-Castellano; serba en ALEANR, II, $* 181$.

\section{SILVAR}

(Sorbus domestica)

Rosáceas

Arbolillo próximo al serbal con yemas lampiñas y viscosas. Flores blancas o rosadas y frutos semejantes a pequeñas peritas verdes grisáceas o parduzcas, encanecidas y de sabor áspero. Sus frutos son comestibles y se elaboran licores. Se encuentra silvestre y cultivado en bosques y setos del piso inferior. Tiene propiedades astringentes, es antiescorbútico y rico en taninos. 
$\mathrm{DL}$ silva (B), (BEC); silvar (BEC), (CyV); silvia, viforal y vifural (BEC).

OV: silva 'fruto del serbal; serba en Castilla. Úsase en Astorga' (Maragatería y A.), Alonso Garrote; Acad. silva, ant. serba, úsase en León 'arbusto que da peritas tardías y ásperas'.

\section{SACARRILLOS}

(Dorycnium pentaphyllum)

Leguminosas

Arbustillo con foliolos lineales y sin peciolo. Las flores son blancas con la quilla negruzca sobre cabezuelas redondeadas y axilares. Fruto inflado con varias semillas. Es una especie variable. Florece en abril y se cría en lugares herbosos y bordes de caminos.

DL: tomilla y zurravieja (BEC), (CyV); tomillina (MyA), (CyV).

\section{TORAY}

(T a maris gallica)

Tamaridáceas

Arbusto muy ramificado y flexible con corteza pardo-rojiza, hojas menudas, elípticas, glaucas y abrazadoras en la base. Flores diminutas, rosadas o blancas, en largas espigas que crecen al final de las ramas. El fruto es seco y capsular. Florece en abril, y se cría en riberas y zonas pantanosas. Es tintóreo y se ha empleado para fijar terrenos, y en medicina popular, contra diarreas y disenterías.

DL: chamariz (CyV).

OV: tarabe o taraye 'taray o taraje', tarajal 'sitio poblado de tarajes, tarahes o tarayes' (Andal.), Alcalá V.

\section{TEJO}

( $\mathrm{T}$ a x u b a c a t a)

Taxáceas

Árbol perennifolio con corteza escamosa y ramas casi horizontales. Hojas lineales, estrechas y puntiagudas. Flores poco visibles y semilla elipsoidal y carnosa de color rojo. Florece al final del invierno y se cría en terrenos frescos y umbrosos. Hay tejos machos y hembras y suelen crecer aisladamente. Es tóxica y se usa como ornamental en los cementerios.

$\mathrm{DL}$ i tejo (ML), (B), (MR), (CyV); teiso (CyV); tesio (MR); teixo y texeira (B).

OV: teiẍo 'tejo', 'árbol siempre verde. Con el zumo del tejo se envenenaban los cántabros para no venderse a los romanos, y de su nombre 
deriva el to x i c u m o tósigo que se aplica a todos los venenos' (bable occid.), Acevedo; teišo (Cabrera), Casado; tišu (Lena), Neira; teixo (bable occid.), Rodríguez-Castellano, tesio (Sajambre), Fernández González; teixu (Sisterna), J. A. Fernández; tiju (Pas), Penny; tejo en ALEANR, III, *396.

\section{TILO}

(Tilia plantyphyllos)

Tiliáceas

Árbol de corteza lisa y cenicienta; hojas acorazonadas con márgenes irregularmente dentados y flores olorosas blanco-amarillentas. Fruto redondo y velloso. Florece en junio y se cría en bosques con otros árboles. Las flores son sedantes y se utilizan para calmar la excitación nerviosa y aminorar la acidez de estómago.

$\mathrm{DL}$ : tilo (BEC), (B), (MR); tilar (MR), (BEC); tiral y tilal (MR).

OV: teja 'tilo silvestre' (Santander), García Lomas; tella 'tilo' (Jaca), Alvar; tella y tillero (Aragüés), González Guzmán; teya y tilar (Lena), Neira; tileiro, techa, tilano (bable occid.), Rodríguez-Castellano; techa (Sisterna), J. A. Fernández; tellera (A. Ribagorza), Haensch; tileru (El Rebollar), Iglesias; tilo en ALES, 238.

\section{TOJO}

(Ulex europaeus)

Leguminosas

Arbusto muy ramificado y provisto de espinas laterales muy punzantes. Hojas ovales, estrechas puntiagudas. Flores amariposadas de color amarillo dorado. El fruto es oval y comprimido. Florece a partir de enero y se cría en matorrales, setos y brezales desprovistos de cal. Se ha utilizado como planta forrajera y su uso no es aconsejable por ser tóxico; sus hojas se han empleado para tratar afecciones hepáticas.

$\mathrm{DL}$ : tojo (CyV), (MyA), (B), (BEC); tocho y toitso (B); toyo, toiso (MyA), $(\mathrm{CyV})$; árgoma y árguma (ML) y (MR); toco y tocio (BEC).

OV: tö̈o 'tojo', 'sirve para roxar el horno; y la parte más leñosa, que es muy dura, se utiliza para el fuego de las cocinas y para hacer los gayardos o cayados, con que se juega a la choca, y aún para bastones. La semilla se llama navia de tö̈o. Us. en muchos concejos de Asturias alternando con to $\ddot{x}$; el matorral de tejos verdes jóvens verdeña; cuando es de tojos viejos altos y espesos se llama bouza' (bable occid.), Acevedo; toyo 'tojo' (Maragateria y A.), Alonso Garrote; escajo 'aulaga, árgoma'; escajera 'lugar poblado de escajos'; escajal 'argomal' (Santander), García Lomas; cotolla 'árgoma' y cotollal 'argomal' (Colunga), Vigón; iscaju 
'árgoma o aulaga'; el argomal árguma, iscajal (Pas), Penny; toxo 'aliaga o tojo'; hay dos clases: manso, que es el que se siembra en terrenos de labor y bravo el que crece espontáneo, en terreno incultivable; éste se diferencia poco del árguma (bable occid.), Rodríguez-Castellano; toxu 'tojo' (Sisterna), J. A. Fernández.

\section{TOMILLO BLANCO/MEJORANA}

(Thymus mastichina)

Labiadas

Arbustillo con tallos leñosos, derechos y hojas de figura aovada, lanceolada y con bordes revueltos. Las flores de color rosa amarillento, verdosas o blancas, se agrupan en cabezuelas terminales aromáticas; fruto seco, con semillas redondeadas. Florece en primavera y se cría en laderas soleadas, tierras bajas y páramos. Sus flores se han utilizado como antiespasmódicas y para estimular la circulación.

DL: tomillo (todos); tumillo (B), (CyV); tomillo de flor blanca y tomillo sarpotsu, var. (ML); tomillo blanco, tomillo corriente, tomillo oloroso, mejorna y tomillo salcedo (BEC).

OV: almarauje 'variedad de tomillo que crece en las vegas de los de los ríos. Su flor es parecida a la de la mejorana y es muy olorosa' (Belalcázar, Córdoba), saladillo 'especie de tomillo sin olor', borriquero 'variedad de tomillo de aroma muy fuerte y flor roja. De este se extrae el timol' (Belalcázar, Córdoba) (Andal.), Alcalá V.; sarposu 'una variedad de tomillo' (Aragüés), González Guzmán; galana 'flor del tomillo' (MyA), Alonso Garrote; tomiño 'tomillo', tomaza 'tomillo grande menos oloroso que el pequeño', urgaza 'especie de tomaza; el lugar abundante de tomazas es el tomazar' (Rioja), Goicoechea; tomillo en ALA, 757; ALC, V, 800; ALEANR, III, *285; ALVA, 791.

\section{TOMILLO SALSERO}

(Thymus zigis)

Labiadas

Arbustillo aromático muy ramificado, con hojas estrechas linearlanceoladas. Las flores, rosadas o blancas, nacen en espigas. El fruto es seco, con pelos para favorecer la diseminación. Florece en primavera y se cría en suelos pobres y zonas de vegetación degradada. De olor agradable se emplea como condimento y adobo; sus hojas y flores tienen propiedades tónicas y sirve de analgésico local.

DL: tomillo sanjuanero, sanjuanes, tomillo de flor morada, tomillo serrillo, tomillo salsero, tomillo rastrero (BEC); tomillo de flor rojiza (ML); tomillina (MyA) y tomillo zaucero (MR). 
OV: tomilleja 'tomillo sensero', este tomillo, que adopta tantos y tan distintos nombres en la Ribera, en la mayor parte de la provincia se conoce con la denominación de tomillo salsero, también escarqueja, jenjerina, salserilla (La Ribera), Llorente; tomillina 'tomillo salsero de planta y hoja más pequeña que la del tomillo común y olor muy agradable. Ejemplo dialectal de cambio de género, tomillina, de tomillín, tomillo pequeño' (Maragatería y A.), Alonso Garrote; tremonsillo y timonet (A. Ribagorza), Haensch; tombillo (Anguiano), Echaide; sensero (Béjar), Marcos; tomillo ancinoso, tomillo salao, tomillo borriquero y tomillo de las fustas (La Roda), Chacón; tomillo y tumillo (Sayago), Borrego; salsero, morquera, común y ratero (Cuenca), Calero.

\section{TORVISCO}

(Daphne gnidium)

Timeleáceas

Arbusto de tallos grisáceos, hojas gruesas, coriáceas, de color oscuro brillante. Flores amarillo verdosas y blancas, en racimillos terminales. Fruto ovoide, negro y carnoso. Florece en abril y se cría en bosques abiertos, matorrales y roquedos. Las hojas, el fruto y la corteza, aunque son eméticos y venenosos, se han utilizado para limpiar heridas.

DL: torvisco y toroviscu (BEC); truvisco (MyA).

OV: azuqueca 'torvisco, mata' (Sierra de Segura, Jaén); bolaga, id. (Cádiz); espantamoscas y espantapulgas 'torvisco, arbusto' (provincia de Jaén); granilla y torvisquina, 'baya del torvisco y del lentisco' (Andal.), Alcalá V.; torbisco 'arbusto de la familia de los euforbiáceas, machacándolo en gran cantidad y dentro de un saco, su jugo venenoso se aplica para matar truchas y pescar' (Bierzo), García Rey; boliaga y culopollo 'planta montaraz' (Orihuela), Guillén; torvisca (Coria), Cummins; torvisco (La Roda), Chacón.

\section{UVA ESPINA}

(R ibes uva-cris pa)

Saxifragáceas

Arbustillo parecido a la grosella con tallos armados de fuertes espinas, y flores solitarias o dispuestas en hacecillos de color verde amarillento y su fruto, semejante a las uvas, es de color verdoso, amarillento o púrpura. Se cría en setos, matorrales y tierras abandonadas. Su fruto comestible es astringente y se fermentaba para obtener vino de grosella.

DL: cerremingano, zarramingano, remingano, zaramúngano, zarremingano (BEC). 


\section{ZARZA}

(Rubus ulmifolius)

Rosáceas

Arbusto sarmentoso con espinas y tallos leñosos; hojas con foliolos desiguales y márgenes dentados. Flores blancas o rosadas en racimos terminales; el fruto es la mora o zarzamora; al principio roja y al madurar negra, está constituida por numerosos frutículos. Florece a finales de mayo y se cría en ribazos, setos y matorrales. Sus frutos se emplean contra la diarrea, disentería e inflamaciones de garganta.

DL: zarza (B), (BEC), (CyV), (MyA), (ML); zarzamora (BEC), (B), (CyV); zarza morera (ML), (BEC); zarzal (BEC), (MyA); zarza de mora negra y zarza de mora encarnada (MyA); amural (ML); bardal y bardo (MR).

OV: silva 'zarzamora' y silveira 'zarzal', y moreiras 'zarzamora' (bable occid.), Acevedo; silvar 'zarzamora' (La Ribera), Llorente; mora 'zarzamora', sarza 'zarza', sarzal 'zarzal', raja 'zarzamora' y rajal 'matorral de zarzamoras', barda 'zarzamora', zarzal y bardal 'mata de moras' (Santander), García Lomas; amora 'mora, fruto' (Cabranes), Canellada; amural 'zarza' y amora 'fruto' (Babia y L.), Álvarez González; zarzamorra 'zarzamora' y charga 'zarzal del moral' (Jaca), Alvar; mora 'fruto de la morera' y barzal 'garza o zarza' (Bielsa), Badía; artal 'zarzal' (A. Aller), Rodríguez-Castellano; id. (Lena), Neira; charra, charguera, barza 'zarza', barzal el zarzal (Aragüés), González Guzmán; artu 'zarzamora' y escayu 'zarza'; escayu negral 'espino negro' (Colunga), Vigón; balseiro, bardal y zarzal, bardón 'zarzal muy espeso', arto 'zarzamora' y amoura 'fruto de la zarzamora' (bable occid.), Rodríguez-Castellano; morianga 'zarzamora' (Tenerife), Alvar; bardal 'zarzal' y bardos 'zarzales que dan moras' (Sisterna), J. A. Fernández; barsa 'zarza' (A. Ribagorza), Haensch; barda 'zarza, matorral' (Rioja), Goicoechea; urias 'zarzas' y jaral, bardal 'zarzal' (Pas), Penny; escayu 'zarza, espino de arbusto' y escayal 'sitio abundante de espinos' (Cabo Peñas), Díaz; zarza en ALA, 188; ALC, III, 228; ALES, 959; ALVA, 227.

\section{BIBLIOGRAFIA}

Bernardo ACEVEDO y Huelves y Marcelino FERNÁNDEZ y FERNÁNDEZ, Vocabulario del bable de occidente (Madrid, 1932).

Antonio AlCAlÁ Venceslada, Vocabulario andaluz (Madrid: RAE, 1951).

S. ALONSO GARROTE, El dialecto vulgar leonés bablado en Maragatería y Tierra de Astorga (Madrid: CSIC, 1947).

Manuel Alvar, El babla del Campo de Jaca (Salamanca: CSIC, 1948).

- El español bablado en Tenerife (Madrid: CSIC, 1959). 
Guzmán ÁlVAREZ, El babla de Babia y Laciana (Anejo XLIX de la RFE, Madrid: CSIC, 1949). Jesús Álvarez FERNÁNDEZ-CAÑEDO, El habla y la cultura popular de Cabrales (Anejo LXXVI de la RFE, Madrid: CSIC, 1963).

Antonio BADIA MARGARIT, El babla del Valle de Bielsa (Barcelona: CSIC, 1950).

José María BAZ, El habla de la tierra de Aliste (Anejo LXXII de la RFE, Madrid: CSIC, 1967).

Julio BORREgo NIETO, Sociolingüistica rural. Investigación en Villadepera de Sayago (Salamanca: Universidad de Salamanca, 1981).

José Luis CALERO, Nombres vernáculos de la flora conquense (Cuenca, 1989).

María Josefa CANELlADA, El babla de Cabranes (Anejo XXXI de la RFE, Madrid: CSIC, 1944).

M." Concepción CASADO LOBATO, El habla de la Cabrera Alta (Contribución al estudio del dialecto leonés) (Anejo XLIV de la RFE, Madrid: CSIC, 1948).

Andrés CEBAllos JIMÉnEz, Diccionario ilustrado de los Nombres vernáculos de las plantas de España (Madrid: ICONA, 1986).

Joan Corominas y José Antonio PASCual, Diccionario crítico-etimológico castellano e bispánico (Madrid: Gredos, 1980).

John G. Cummins, El babla de Coria y sus cercanias (London: TBL, 1974).

Teudiselo Chacón Berruga, el babla de la Roda de la Mancha (Madrid: CSIC-Instituto de Estudios Albaceteños, 1981).

Carmen Díaz Castañón, el bable de El Cabo Peñas (Oviedo: CSIC-Instituto de Estudios Asturianos, 1966).

DiCCIONARIO de la Lengua Española de la Real Academia Española (Madrid, 1992). Citado como Acad.

Ana María Echaide y Carmen SARAlegui, El habla de Anguiano (Logroño, 1972).

Joseph A. FFrnánDEZ, El habla de Sisterna (Anejo LXXIV de la RFE, Madrid: CSIC, 1960).

Angel Raimundo Fernández GonzÁlez, El babla de Oseja de Sajambre (Oviedo: CSICInstituto de Estudios Asturianos, 1959).

Pío FonT QUeR, Plantas medicinales. El Dioscórides renovado, (Barcelona, Edit. Labor, 1990).

Vicente GARCÍA DE DIEgo, Diccionario etimológico español e bispánico (Madrid: Saeta, 1954).

Adriano Garcia LOMAS, El lenguaje popular de las montañas de Santander (Santander: Diputación Provincial, 1949).

Verardo GARCía REY, Vocabulario del Bierzo (León: Edit. Nebrija, 1979). (Edic. facsímil).

Cesáreo Goicoechea, Vocabulario riojano (Anejo IV del BRAE, Madrid, 1961).

Fidel GonzÁlez, "Vocabulario de uso frecuente en la montaña leonesa", RDTP, XXV (1969), pp. $357-361$.

Pascual González Guzmán, El habla viva del Valle de Aragüés (Zaragoza: CSIC, 1953).

Fernando GONZÁLE Ollé, El habla de la Bureba. (Introducción al castellano actual de Bungos) (Anejo LXXVIII de la RFE, Madrid: CSIC, 1964.

José Guillén GARCiA, El babla de Oribuela (Alıcante: CSIC-Instituto de Estudios Alicantinos, 1974).

Günther Haensch, Las hablas de la Alta Ribagorza. (Pirineo Aragonés) (Zaragoza: Institución Fernando el Católico, 1960).

Ángel Iglesias OVejero, El babla de El Rebollar (Salamanca, 1982).

Fritz KRUGer, El dialecto de San Ciprián de Sanabria (Anejo IV de la RFE, Madrid: CSIC, 1923).

Ginés LÓPEZ GONZALEZ, La guia de INCAFO de los árboles y arbustos de la Península Ibérica (Madrid, 1991).

M.* Angustias Luzón, Indices léxicos de los Atlas Lingüusticos Españoles (Madrid: ICI, 1987).

Antonio LLORENTE MALDONADO DE GUEVARA, Estudio sobre el habla de la Ribera (Salamanca: CSIC, 1947).

Manuel Antonio Marcos Casquero, El babla de Béjar (Salamanca, 1979).

José MILLÁN URdiales, "El habla de Villacidayo (León)", BRAE (1966).

César MORÁN, "Vocabulario del Concejo de La Lomba en las montañas de León", BRAE, XXX (1950). pp. 155-168, 313-330 y 439-456. 
Antonio MURGa BoHIGAS, Habla popular de Extremadura (Madrid: Alvi, 1979).

Jesús NeIra Martínez, El babla de Lena (Oviedo: CSIC-Instituto de Estudios Asturianos, 1955).

Ángel Penas, Justino DiEz, Félix Llamas y Mario Rodríguez, Plantas Silvestres de Castilla y León (Valladolid: Ámbito, 1991).

Ralph J. PENNY, El babla pasiega: ensayo de dialectología montañesa (London: Tamesis Books, 1970).

Oleg Pulinin, Guía de Campo de las flores de Europa (Barcelona: Omega, 1982).

Lorenzo RODRíguez-CASTEllano, La variedad dialectal del Alto Aller (Oviedo: CSIC, 1982).

- Contribución al vocabulario del bable occidental (Oviedo: CSIC-Instituto de Estudios Asturianos, 1957).

Fernando Rubio Álvarez, "Vocabulario dialectal del Valle Gordo (León)», RDTP, XVII (1961), pp. 264-320.

Enrique SÁnchez-MOnge y PAREllada, Diccionario de Plantas Agrícolas (Madrid: Ministerio de Agricultura, 1981).

Máximo TORReblanca EsPinOSA, Estudio del babla de Villena y su comarca (Alicante: CSICInstituto de Estudios Alicantinos, 1976).

Braulio Vıgón, Vocabulario dialectológico del Concejo de Colunga (Anejo LXIII de la RFE, Madrid: CSIC, 1955).

Fidel Villarroel, "Ensayo de un vocabulario tejerinense. El léxico típico del pueblo de Tejerina en la montaña leonesa», RDTP, XXXI (1975), pp. 3-62.

Alonso ZAMORA VICENTE, El babla de Mérida y sus cercanias (Anejo XXIX de la RFE, Madrid: CSIC, 1943).

- Léxico rural asturiano. Palabras y cosas de Libardón (Colunga) (Granada, 1953).

\author{
Manuel Agustín Esgueva Martínez \\ UNED, Madrid
}

He recogido en el presente trabajo las denominaciones de los diferentes vegetales de la provincia de León. Las encuestas se han hecho "in situ", fotografiando la planta, transcribiendo el nombre vernáculo y luego verificando los ejemplares recogidos en el laboratorio de botáncia. Doy el nombre oficial, la denominación científica y la familia botánica; hago una breve descripción y doy los nombres de uso común de cada especie y el área donde los he recogido. Las voces registradas están hechas con exactitud fonética y geográfica; por otro lado, el conocimiento de los diferentes nombres de las diversas comarcas nos da una visión del leonés actual y las denominaciones que se utilizan en otras partes de España.

In this work I have collected the denominations of the different vegetables of Leon province. The questions have been made in situ", doing photographs of the plants, with the transcription of the name as is known in the place of origin and in the laboratory identifying the samples collected. I give the usual name and also the scientific denomination and the botanic family; I give a brief description and the names of common use of every plant and the place where I have collected them. The registered names have been taken with phonetic and geographic exactitude. Besides the knowledge of the different names of the diverses regions gives us a clear perspective of actual Leones language and the denominations that are used in other parts of Spain. 